\title{
\begin{tabular}{r|l} 
Environment & Lancaster \\
Centre & University
\end{tabular}
}

\section{Development of a Solar Park Carbon Calculator (SPCC) to assist deployment decisions}

By

Ryan Holland

As part of a MSc By Research Environmental Science for Lancaster Environment Centre

June 2021

Supervised by

Dr Alona Armstrong \& Dr Fabio Carvalho G da Silva 


\section{Abstract}

Following the Paris agreement, many nations have committed to targets of net zero emissions, resulting in a significant increase in low-carbon energy generation. Recent improvements in the cost and efficiency of photovoltaic (PV) technology has made it highly competitive, with the uptake of PV projected to surpass fossil fuels by 2035. Large-scale, ground-mounted solar parks are likely to constitute a considerable portion of this expansion. Despite the expansion of solar parks and the associated land use change, there is very little understanding of the environmental implications. In particular, the effect on ecosystem carbon cycling, and thus the decarbonisation attraction of the technology, is unknown. Here, we complete a systematic review of existing renewable energy carbon calculators, identifying carbon stocks and flows during construction, operational and decommissioning life-cycle phases. This insight is used to develop an idealised solar park carbon calculator (SPCC) that quantifies the full suite of solar park technological and ecological carbon impacts. We determine the carbon stocks and flows for solar parks drawing on established quantifications for system components, operation, and land management. Key components include the emissions factors for production of panels and mounts, machinery related emissions and the associated carbon flows of ground disturbances, before and after park construction. Carbon emissions offset by replacing grid mix electricity with that generated by the solar park are also included to provide an estimate of carbon payback time. Recommendations are provided as to how carbon payback time can be reduced, including manufacturing components with low-carbon energy, and avoiding placement on areas of high ecosystem carbon (e.g., peatlands). Finally, critical knowledge gaps, uncertainties and future options for development are outlined. The SPCC can help inform solar park developer decisions in order to minimise carbon costs and maximise carbon sequestration, ultimately helping to meet net zero goals. 


\section{Acknowledgements}

I would firstly like to thank $\operatorname{Dr}$ Alona Armstrong \& Dr Fabio Carvalho $G$ da Silva for their supervision and overwhelming support throughout the project, it has been a pleasure to work with them within the Energy-Environment group, even during the difficult circumstances the last year has brought. I would like to thank Hollie Blaydes for providing me access to her digitised maps of solar parks and associated data. Thanks to Giles Exley, Aneurin O'Neil, Sam Robinson and Lucy Treasure, along with any others who provided guidance or feedback on my work. I would like to thank all of the industry experts who contributed to this project through the professional insight they provided, of which there are too many to name here. I would like to thank the LEC Postgraduate staff for assisting with my many administrative queries. I would also like to thank my mother, Margaret, father, Philip, and sister, Rebecca for supporting me in completing this project as they have done with all other pursuits I have undertaken. Finally, I would like to thank Energy Lancaster for providing funding for this project, without which none of this could have taken place.

\section{Author's Declaration}

I declare that this thesis is my own work and has not been submitted in substantially the same form for the award of a higher degree elsewhere. Any sections of the thesis which have been published, or submitted for a higher degree elsewhere, shall be clearly identified. 


\section{Contents}

$\begin{array}{lr}\text { Abstract } & 2\end{array}$

Acknowledgements $\quad 3$

Author's Declaration 3

$\begin{array}{lr}\text { Contents } & 4\end{array}$

$\begin{array}{lc}\text { List of Figures } & 8\end{array}$

$\begin{array}{lr}\text { List of Tables } & 8\end{array}$

$\begin{array}{lr}\text { List of Appendices } & 8\end{array}$

$\begin{array}{lr}\text { Definitions } & 9\end{array}$

$\begin{array}{ll}1.0 \text { Introduction } & 11\end{array}$

1.1 Emissions Targets \& Renewables 11

1.2 Solar \& Land Use Change 11

1.2.1 Environmental impacts of land use change for solar parks 13

1.3 Grasslands as carbon stores 13

1.3.1 Soil Carbon Stocks 13

$\begin{array}{ll}\text { 1.3.2 Grassland carbon cycling } & 14\end{array}$

1.4 Solar Park perturbation of Carbon Cycling 15

1.4.1 Construction and Decommissioning impacts 15

$\begin{array}{ll}1.4 .2 \text { Operational impacts } & 16\end{array}$

$\begin{array}{ll}\text { 1.4.3 Land management impacts } & 17\end{array}$

$\begin{array}{ll}1.5 \text { Carbon intensity of solar park electricity } & 17\end{array}$

1.6 Aim and objectives 18

$\begin{array}{ll}\text { 2.0 The Current State of Carbon Calculators } & 19\end{array}$

2.1 Introduction 19

2.2 Methods 20

2.2.1 Carbon Calculator Review $\quad 20$

$\begin{array}{ll}2.2 .2 \text { Literature search } & 21\end{array}$

$\begin{array}{ll}2.2 .3 \text { Literature screening } & 21\end{array}$

2.2.4 Information extraction $\quad 21$

2.2.5 Information analysis $\quad 22$

2.3 Results 22

2.3.1. Overview 22

2.3.2 Life cycle stages 24

2.3.2.1 Resource Extraction $\quad 25$

2.3.2.2 Transport 25

2.3.2.3 Production 25 
2.3.2.4 Installation $\quad 26$

$\begin{array}{ll}\text { 2.3.2.5 Operation } & 26\end{array}$

2.3.2.6 Decommissioning $\quad 26$

$\begin{array}{ll}\text { 2.3.2.7 Energy offset } & 26\end{array}$

2.4 Discussion $\quad 30$

2.4.1 Separation of carbon flows in all lifecycle stages $\quad 30$

2.4.2 Improving understanding of ecosystem carbon impacts 30

2.4.3 Advancing understanding of decommissioning carbon stocks and flows 31

2.4.4 Incorporating temporal dynamics 32

2.5 Conclusions

3.0 Development of a Solar Park Carbon Calculator 34

$\begin{array}{ll}3.1 \text { Rationale } & 34\end{array}$

3.2 Methods $\quad 36$

3.2.1 Idealised SPCC framework development 36

$\begin{array}{ll}3.2 .1 .1 \text { Knowledge base } & 36\end{array}$

3.2.1.2 SPCC terminology $\quad 37$

3.2.2 Resolution of carbon stocks and flows 38

$\begin{array}{ll}3.3 \text { Results } & 41\end{array}$

3.3.1 Idealised SPCC Framework $\quad 41$

3.3.2 Resolution of carbon stocks and flows $\quad 44$

3.3.3 Construction - Technological $\quad 44$

3.3.3.1 Manufacturing of components $\quad 44$

3.3.3.1.1 Panels: $\quad 44$

3.3.3.1.2 Mounts: $\quad 45$

3.3.3.1.3 Cabling: $\quad 45$

3.3.3.1.4 Inverters: $\quad 46$

3.3.3.1.5 Switchgear/transformers: $\quad 46$

3.3.3.1.6 Fencing: $\quad 47$

3.3.3.1.7 Other Raw Materials: $\quad 47$

3.3.3.2 Transportation of components 48

$\begin{array}{ll}\text { 3.3.3.3 Machinery Use } & 49\end{array}$

$\begin{array}{ll}\text { 3.3.3.4 Additional resource use } & 49\end{array}$

3.3.4 Construction - Ecosystem $\quad 49$

3.3.4.1 Soil carbon $\quad 49$

3.3.4.1.1 Complete land surface coverage $\quad 50$

3.3.4.1.2 Shading $\quad 51$

3.3.4.1.3 Open areas $\quad 51$

3.3.4.2 Aboveground Biomass $\quad 52$

3.3.4.2.1 Complete coverage $\quad 52$

3.3.4.2.2 Shading $\quad 53$

3.3.4.2.3 Open Areas $\quad 53$

3.3.4.3 Construction practices $\quad 53$

3.3.5 Operational - Technological $\quad 54$

3.3.5.1 Offsetting potential $\quad 54$

3.3.5.2 Missing components $\quad 54$

3.3.6 Operational - Ecosystem $\quad 55$

3.3.6.1 Soil Carbon $\quad 55$

3.3.6.2 Aboveground Biomass $\quad 55$

3.3.6.3 Management Interventions $\quad 55$ 
3.3.7 Decommissioning $\quad 55$

3.3.7.1 Technological $\quad 56$

3.3.7.2 Ecosystem $\quad 56$

3.3.8 Carbon Payback Time $\quad 56$

$\begin{array}{ll}3.4 \text { Discussion } & 57\end{array}$

3.4.1 Construction - Technological $\quad 57$

$\begin{array}{ll}\text { 3.4.1.1 Manufacture of components } & 57\end{array}$

$\begin{array}{ll}\text { 3.4.1.1.1 Panels } & 57\end{array}$

3.4.1.1.1 Mounts $\quad 58$

3.4.1.1.2 Cabling $\quad 59$

3.4.1.1.3 Inverters $\quad 59$

3.4.1.1.4 Switchgear, transformers, and battery storage $\quad 60$

$\begin{array}{ll}3.4 .1 .1 .5 \text { Fencing } & 60\end{array}$

3.4.1.1.6 Other Raw Materials $\quad 60$

3.4.1.2 Transportation of components $\quad 61$

$\begin{array}{ll}\text { 3.4.1.3 Machinery emissions } & 61\end{array}$

3.4.1.4 Additional resource use during construction $\quad 62$

3.4.2 Construction - Ecosystem $\quad 62$

$\begin{array}{ll}\text { 3.4.2.1 Soil Carbon } & 62\end{array}$

3.4.2.1.1 Complete Coverage $\quad 63$

$\begin{array}{ll}3.4 .2 .1 .1 .1 & \text { Access tracks }\end{array}$

$\begin{array}{ll}3.4 .2 .1 .1 .2 & \text { Buildings }\end{array}$

3.4.2.1.1.3 Construction compound $\quad 64$

3.4.2.1.2 Shading $\quad 64$

3.4.2.1.3 Open Areas $\quad 64$

3.4.2.1.4 Construction Impacts $\quad 65$

$\begin{array}{ll}3.4 .2 .1 .4 .1 & 65\end{array}$

3.4.2.1.4.2 Compaction $\quad 66$

3.4.2.1.4.3 Trenching $\quad 66$

$\begin{array}{ll}\text { 3.4.2.2 Aboveground biomass } & 67\end{array}$

$\begin{array}{ll}\text { 3.4.2.2.1 Complete land coverage } & 67\end{array}$

$\begin{array}{ll}\text { 3.4.2.2.2 Shading } & 67\end{array}$

$\begin{array}{ll}\text { 3.4.2.2.3 Open Areas } & 67\end{array}$

$\begin{array}{ll}\text { 3.4.2.2.4 Construction Impacts } & 68\end{array}$

3.4.3 Operational - Technological $\quad 68$

$\begin{array}{ll}\text { 3.4.3.1 Electricity generated/offset } & 68\end{array}$

$\begin{array}{ll}\text { 3.4.3.2 Backup generation } & 70\end{array}$

3.4.3.3 Manufacture of replacement components $\quad 70$

3.4.3.4 Machinery \& resource use for maintenance $\quad 71$

$\begin{array}{ll}\text { 3.4.3.5 Energy use during operation } & 71\end{array}$

$\begin{array}{ll}\text { 3.4.4 Operational - Ecosystem } & 71\end{array}$

$\begin{array}{ll}\text { 3.4.4.1 Land Cover Change } & 71\end{array}$

$\begin{array}{ll}\text { 3.4.4.2 Management practices } & 72\end{array}$

3.4.5 Decommissioning - Technological 73

3.4.5.1 Machinery emissions from decommissioning $\quad 73$

3.4.5.2 Transport to waste management facilities $\quad 73$

$\begin{array}{ll}\text { 3.4.5.3 Recycling } & 73\end{array}$

3.4.6 Decommissioning - Ecosystem $\quad 74$

$\begin{array}{ll}\text { 3.4.6.1 Soil } & 74\end{array}$

3.4.6.1.1 Impact on natural carbon processes of deconstruction activities $\quad 74$

$\begin{array}{ll}\text { 3.4.6.1.2 Land use change } & 75\end{array}$

$\begin{array}{ll}\text { 3.4.6.2 Aboveground biomass } & 75\end{array}$ 
3.4.6.2.1 Impact on natural carbon processes of deconstruction activities

3.4.6.2.2 Land use change

3.4.7 Carbon Payback Time

3.4.8 Critical research needs

3.4.8.1 Time element

3.4.8.2 Data Gaps

\subsection{Discussion \& Conclusions}

4.1 Challenges with quantification of carbon stocks and flows

4.1.1 Knowledge gaps

4.1.2 Uncertainty with information

4.2 Using the tool to minimise carbon emissions

4.2.1 Recommendations for technological reductions

4.2.1.1 Utilise tech from low carbon grids

4.2.1.2 Manufacturing company standards

4.2.1.3 Technological advancements

4.2.1.4 Integrating with other renewables and storage

4.2.2 Recommendations for ecological reductions

4.2.2.1 Avoid areas of high ecosystem carbon

4.2.2.2 Best practice construction

4.2.2.3 Good land management

4.2.2.4 Extend solar park lifetimes

4.3 Future tool development

4.3.1 Refining input data

4.3.2 Adding a dynamic temporal component

\section{List of references}

\section{Appendices}

Appendix A

Average Land Coverage $\quad 92$

Rationale

Total Park Area \& Panel Coverage $\quad 92$

$\begin{array}{ll}\text { Fencing requirements } & 93\end{array}$

Access Track \& Building Coverage $\quad 93$

Selecting sample sites $\quad 93$

Access tracks $\quad 93$

$\begin{array}{lr}\text { Buildings } & 94\end{array}$ 


\section{List of Figures}

Figure 1.1 - Figure has been removed due to copyright restrictions.

Figure 1.2 - Locations of UK solar parks.

Figure 1.3 - Figure has been removed due to copyright restrictions.

Figure 2.1 - Graphic demonstrating the number of papers identified at each stage of the search and filtering process.

Figure 3.1 - Visual representation of the idealised SPCC framework.

\section{List of Tables}

Table 2.1 - Database search terms used for the systematic review.

Table 2.2 - Summary of components considered by each renewable energy calculator within the review.

Table 2.3 - Results of the literature search showing renewable energy sources separated by colour.

Table 3.1 - Components quantified within the SPCC and the sources for the associated suggested values.

Table 3.2 - Components quantified within the SPCC and the sources for the associated generic values.

\section{List of Appendices}

Appendix A - Description of the derivation of average land use values within ArcGIS Pro. 


\section{Definitions}

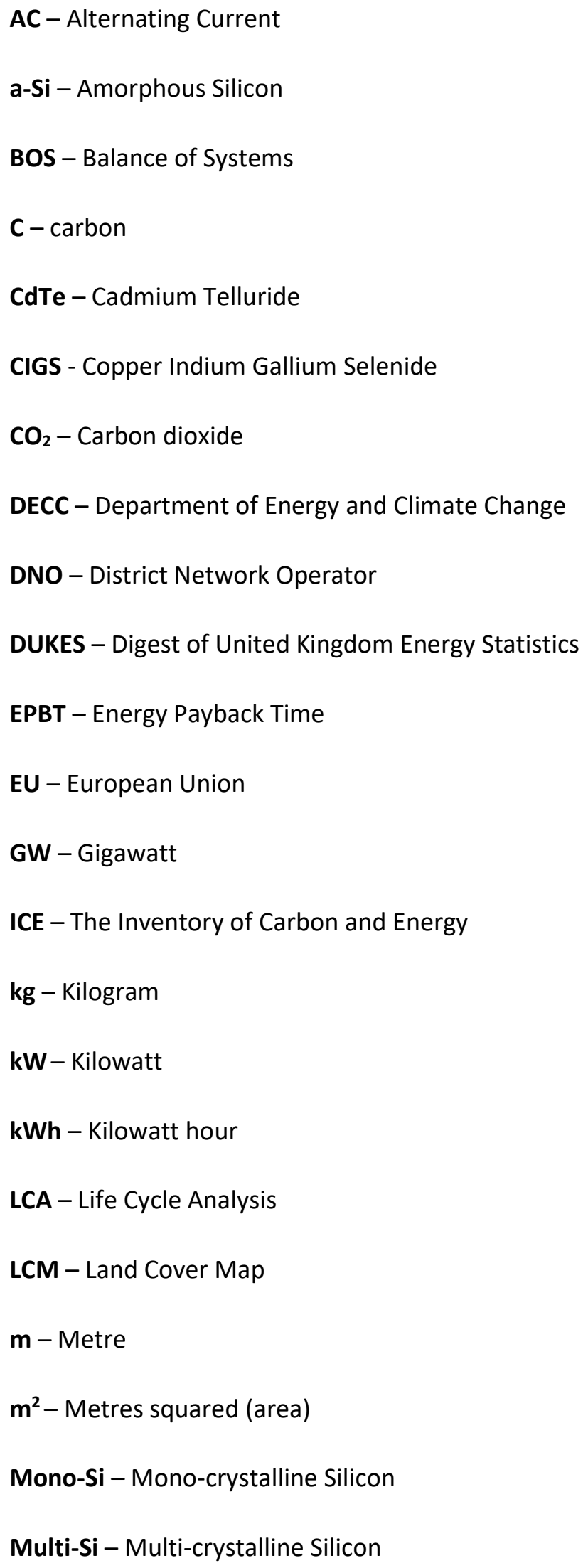


MW-Megawatt

NSI - National Soils Inventory

PV - Photovoltaics

SPCC - Solar Park Carbon Calculator

SPIES - Solar Park Impacts on Ecosystem Services

STVC - Silicon Valley Toxics Coalition TW - Terawatt

TWh - Terawatt hour

UK - United Kingdom

UKCEH - United Kingdom Centre for Ecology \& Hydrology

WEEE - Waste Electrical and Electronic Equipment

$\boldsymbol{\mu m}-\mathrm{Si}$ - “Micromorph" Silicon 


\subsection{Introduction}

\subsection{Emissions Targets \& Renewables}

The UK government's target of net zero $\mathrm{CO}_{2}$ emissions by 2050 has led to a significant increase in low-carbon energy generation (BP, 2019). Targets for nations to achieve 'Net Zero' status are also likely to drive the decarbonisation of energy supplies into the future, with studies projecting renewables will overtake coal in global energy share by 2025 (IEA, 2020). This is partly due to recent improvements in the efficiency of Solar Photovoltaic (PV) technology, making their use more cost effective than new coal and gas fired power stations in a variety of locations (Reichelstein and Yorston, 2013; IEA, 2019). Given this the uptake of PV projected to far surpass fossil fuels by 2035 (IEA, 2019)(Figure 1.1 has been removed due to copyright restrictions).

Solar photovoltaics have accounted for a significant portion UK electricity capacity addition, growing from less than $100 \mathrm{MW}$ installed capacity in 2010 to more than 13,200 MW in 2019 (Solar Trade Association, 2019). Currently 57\% of the UK's current solar capacity comprises of ground-mounted arrays, hereafter solar parks. The Climate Change Committee projects that 54 GW more PV will be required by 2035 to meet net zero targets (Committee on Climate Change, 2019). If the proportion of solar parks remains the same, this is an additional capacity addition of $30.8 \mathrm{GW}$.

Figure 1.1 (Graph demonstrating Installed power generation capacity by source) has been removed due to copyright restrictions

\subsection{Solar \& Land Use Change}

The land take for the current solar capacity is as much as $340 \mathrm{~km}^{2}$ (Randle-Boggis et al., 2020) distributed throughout the UK (see Figure 1.2). The land take could extend to $1871 \mathrm{~km}^{2}$ by 2035 if the Climate Change Committee projection is correct (Committee on Climate Change, 2019; Randle-Boggis et al., 2020). Land use change is known to be a greater threat to nature than climate change (IPBES, 2019), thus understanding the impact of this relatively novel and ever-growing land use change, including implications for ecosystem services and natural capital, is critical. 
Whilst the current and projected land take of solar parks is relatively small compared with the UK's 24.3 million ha area (Solar Trade Association, 2019), it is significant when compared to other land classes such as urban areas. For example, current and projected UK land coverages are $0.1 \%$ and $0.8 \%$ respectively (Committee on Climate Change, 2019; Randle-Boggis et al., 2020), compared to $1.6 \%$ for urban developments (Rowland et al., 2017). Moreover, the land use change to facilitate this solar capacity could bring a number of problems, including putting pressure on the existing 7.2\% of land developed as urban/suburban areas (Rowland et al., 2017), and $23.1 \%$ of land currently used for agricultural purposes (Rowland et al., 2017), as well as missing opportunities for environmental enhancements. Despite this, up until recently there has been limited focus on the potential environmental impacts, especially compared to the focus on trading agricultural production for energy has been related to bioenergy (Djomo and Ceulemans, 2012).

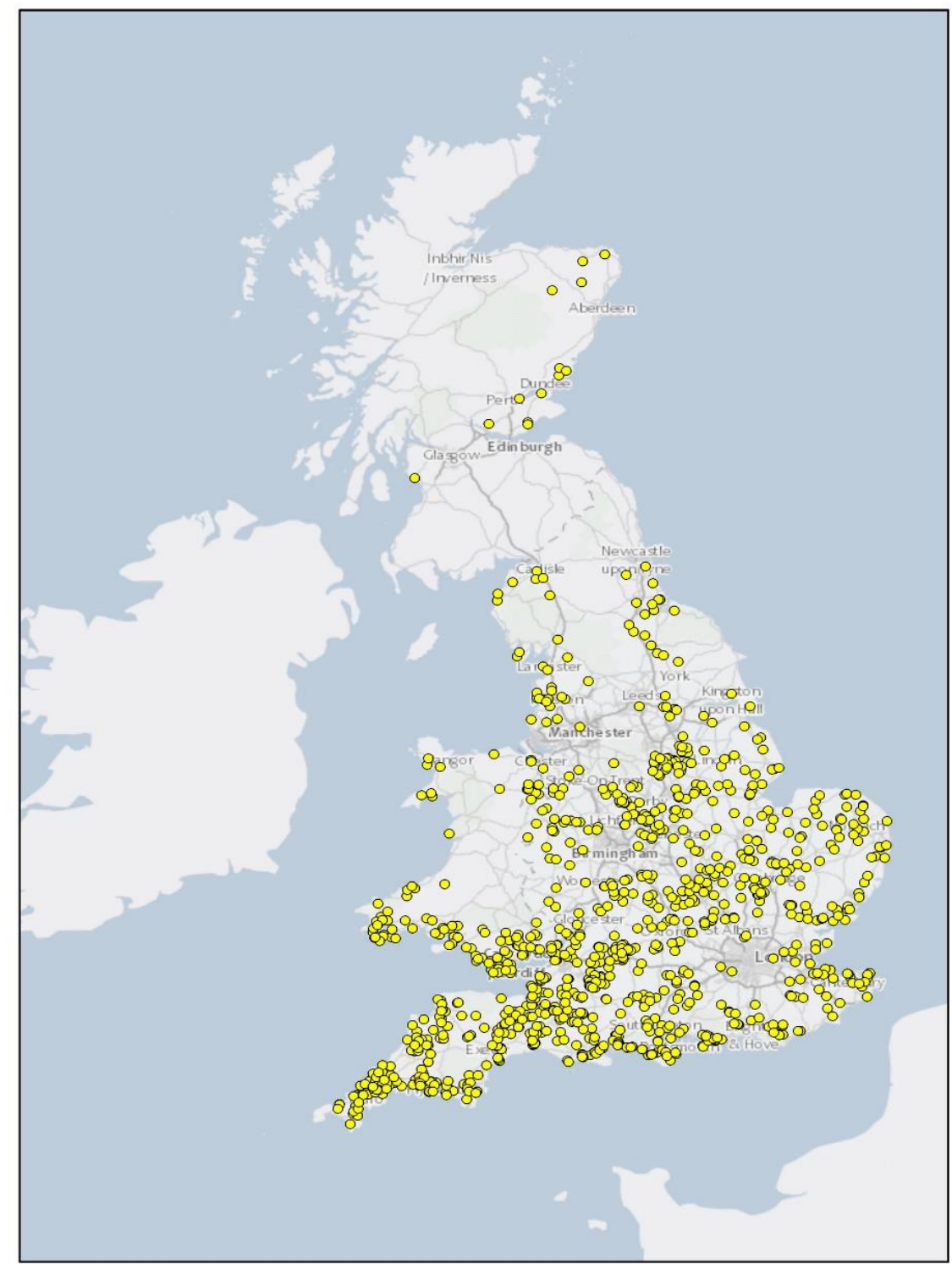


Figure 1.2 - Map of the UK demonstrating locations of UK solar parks (Unpublished data).

\subsubsection{Environmental impacts of land use change for solar parks}

As a consequence of the relatively recent expansion of solar parks, there is relatively little understanding of the environmental impacts. Aside from the impacts on land availability for agriculture and other developments with potential indirect land use changes (Djomo and Ceulemans, 2012), which are often the focus of policymakers and planners, there are the less visible impacts on ecosystem function. These perturbations could have implications for ecosystem services and natural capital of the area subject to land use change. This can include factors such as the natural cycling of carbon, reduced habitats for endangered or endemic species, altered flight or migration paths for animals and birds, or increased collision risk with panel arrays (Taylor et al., 2019). In addition to the impact of the land use change on ecosystem function, site management options could also be influential. For example, the impacts of different grazing regimes, vegetation seeding and the creation of habitats (RandleBoggis et al., 2020).

Implications for soil carbon cycling is of particular importance as it simultaneously impacts the carbon intensity of electricity whilst holding the potential to meet the policy goals of increasing land carbon sequestration. The requirement for the UK to submit annual National Inventory Submissions, to remain compliant with their signing of the Paris Agreement, makes awareness of the carbon sink/source status of an area of land vitally important (UNFCCC, 2015).

\subsection{Grasslands as carbon stores}

\subsubsection{Soil Carbon Stocks}

Although the majority of the land selected for solar parks in the UK is grasslands or poor quality agricultural land (Palmer et al., 2019), these areas are typically managed as grasslands throughout the time of their operation (Armstrong et al., 2016). Therefore, it is important to understand the carbon cycling of these grassland areas to discover where the loss of soil carbon will occur and how it can be minimised. Within the UK, there is $9.8 \pm 2.4$ billion tonnes of carbon stored within the soils (Dawson and Smith, 2007), with around 5.1 billion tonnes of this stored in peat soils, largely in Scotland (Dawson and Smith, 2007). Whilst arablehorticultural land contains around $198 \pm 19$ million tonnes of carbon in the UK, improved grasslands contain $274 \pm 25$ million tonnes (Ostle et al., 2009), suggesting potential for net carbon sequestration as land use changes. There is also a variation in carbon stored in soils 
between grassland types, with Emmett et al. (2010) demonstrating that acid grasslands contained 90.6 tonnes of carbon per ha, compared to 68.6 tonnes carbon per ha for neutral grasslands in 2007. Within grassland ecosystems, the vast majority (around 95\%) of carbon is stored within the soil (Ostle et al., 2009), making the management of soil carbon highly significant.

\subsubsection{Grassland carbon cycling}

Whether or not carbon sequestration will be achieved will depend on the balance of carbon inputs (primarily from vegetation) and outputs from leaching, decomposition, and erosion (Ostle et al., 2009). This cycle is heavily dependent on the climatic conditions of the area in question, including temperature, humidity, precipitation, solar radiation, and wind (Soussana et al., 2004).

Although Milne and Brown (1997) suggests that less than 5\% of the UK's terrestrial carbon is contained within vegetation, it is also deemed a crucial determinant as to whether an area is a carbon sink or source, largely through the contributions of organic matter it makes. Living plants make use of the stores of water and nutrients (primarily N) within the soil, as well as the carbon dioxide in the atmosphere around them to produce new live plant matter and grow. Some of the carbon extracted by these living plants is released to the atmosphere via respiration when photosynthesis cannot take place, but the majority remains within the plant until it is returned to the soil as dead leaves, roots or plant exudates (Soussana et al., 2004). Plant matter such as dead leaves and roots of plants form a layer on the soil, and are decomposed by small insects, bacteria, and fungal matter, producing a carbon rich layer which is gradually covered by new layers of soil and plant matter (Soussana et al., 2004). During this decomposition process there is some level of carbon dioxide produced as the living organisms within the mixture respire and produce energy.

Larger living organisms - which eat the living plants and excrete nutrients onto the soil to aid decomposition (Hillier et al., 2011) - also have an influence on this cycle of carbon being acquired by plants and returned to the soil, particularly when livestock are present. The humidity and temperature are perhaps the two most important factors for the decomposition of dead plant matter and thus the addition of new carbon to the soil (Soussana et al., 2004).

Carbon rich organic matter accumulates over a long process of many years and can remain in the soil almost indefinitely if left undisturbed. However, the top $30 \mathrm{~cm}$ of soil is predicted to contain over half of total soil carbon in the UK (Bradley et al., 2005)(Figure 1.3 has been 
removed due to copyright restrictions), yet this topsoil layer is far more vulnerable to aboveground processes, with up to $90 \%$ of soil carbon changes occurring within the top $30 \mathrm{~cm}$ of soil over decadal processes (Soussana et al., 2004).

Wind and water erosion of soil can also occur, especially in these top layers, removing soil organic carbon and depositing it in other areas. However, both of these processes are greatly reduced when there is sufficient vegetation to maintain the stability of the soil (Guerin, 2017). The quantities of carbon stored in UK soils, and more specifically in the topsoil where land use change could impact, ensured it was critical to suitably quantify the changes in soil carbon flows due to the presence of a solar park.

Figure 1.3 (map representing soil carbon density within the UK) has been removed due to copyright restrictions.

\subsection{Solar Park perturbation of Carbon Cycling}

A solar park, however, has the potential to disturb the cycling of carbon in a number of ways. These disturbances can occur during construction, decommissioning, and during operation, including the impact of land management practices. These carbon impacts can be positive or negative, thus effective planning is vital in ensuring positive outcomes for solar park carbon sequestration.

\subsubsection{Construction and Decommissioning impacts}

Although there is not necessarily any specific requirement for the area to be cleared in preparation for solar panels to be installed, this can occur (Hernandez et al., 2014). However, in the UK solar parks built on grasslands generally experience disturbance, perhaps with the destruction of vegetation, through vehicle disturbance and temporary use of an area as a construction compound. The destruction and covering of vegetation will reduce carbon uptake. In addition, there is likely to be some need to remove soil for the installation of access roads and/or underground cabling as seen in Nayak et al. (2010). Furthermore, the machinery used to construct any of the solar PV facilities may also cause soil compaction, which has been proven to increase emissions of $\mathrm{CO}_{2}$ (Novara et al., 2012). Depending on the previous land use of the area, this land use change to grassland (how the majority of solar parks are managed (Armstrong et al., 2016)), could either result in net gains or losses in soil carbon. Ostle et al. 
(2009) demonstrates how land use change from arable land may result in soil carbon gains, yet changing from forestry to grassland (although this is very unlikely) can result in up to 0.1 tonnes of carbon lost per hectare of land per year.

Although there is much less clarity for the decommissioning phases of solar parks lifetimes, due to no UK parks having currently reached this stage, there is still a potential that these similar impacts will occur again as the reverse construction processes occur.

\subsubsection{Operational impacts}

Once the solar park has been constructed the microclimate of the solar park will be significantly altered. With Armstrong et al. (2016) demonstrating a cooling and drying of areas under solar arrays compared to control areas during summer months. Given climate is a fundamental regulator of carbon cycling, this altered climate could alter both carbon uptake and release. The shading caused by the panels could alter photosynthesis rates, thus growth and carbon inputs. As solar panels prevent up to $65 \%$ of solar radiation reaching the ground (Dupraz et al., 2010), areas covered by panels will have a much lower productive rate than uncovered areas (Armstrong et al., 2016). This variance in solar radiation will also have an impact on local temperature beneath panels compared to surrounding areas (Barron-Gafford et al., 2016), this will not only influence the growth of above-ground biomass but will also have an impact on the decomposition rate. Whilst some papers suggest that this stabilisation could result in increased yields of aboveground biomass (Hassanpour Adeh et al., 2018), Armstrong et al. (2016) demonstrated that in the UK, this may not be the observed impact, with $75 \%$ lower biomass yields below panels.

Vegetation growth and decomposition also depends heavily on the moisture levels of the soil, which are impacted by the presence of a solar park. Hassanpour Adeh et al. (2018) suggests that soil moisture as well as water efficiency was higher under solar panels, with higher biomass of up to $90 \%$. However, in the UK Armstrong et al. (2016) found that there were no significant differences in moisture levels between treatments.

Alongside the decomposition rates, soil erosion rates may be altered. Disturbance of the soil in order to prepare the land for installation of the solar panels (clear and upturn soil (Hernandez et al., 2014)) could lead to increased likelihood of soil erosion via wind. However, Hassanpour Adeh et al. (2018) recorded lower wind speeds under panels compared to above panels, bringing potential for lower wind soil erosion once the panels are in place. Due to the panels acting as a cover, water runoff is concentrated along the edge of the panel (Armstrong 
et al., 2016), this could result in the erosion of soil carbon if there are not sufficient drainage systems in place to prevent this (Smith et al., 2011).

\subsubsection{Land management impacts}

Appropriate land management of solar parks can promote positive environmental outcomes. For example, increases in both botanical and invertebrate diversity (Montag et al., 2016). Hernandez et al. (2014) suggested that soil erosion in solar parks could also be minimized by effective management, which may include the presence of grazing animals and fibre production. Alternatively, Hassanpour Adeh et al. (2018), provided evidence that solar parks could also increase water efficiency of crops in certain regions, bringing potential for further deployment of solar parks and agricultural land in unison. Furthermore, Randle-Boggis et al. (2020) developed the SPIES tool, which gives a comprehensive review of management techniques which can be employed to improve natural capital and ecosystem services of solar parks. Whilst these studies highlight the potential to achieve positive outcomes for ecosystem services and natural capital, Randle-Boggis et al. (2020) also highlights the potential for negative outcomes to come about if effective management techniques are not followed. To date, there is no evidence on the management impacts of solar parks on carbon sequestration despite the implications for the carbon cost of the electricity produced.

\subsection{Carbon intensity of solar park electricity}

Given the need to achieve net zero, resolving the carbon costs of renewable energy technologies is important. Consequently, various assessments have been undertaken, primarily grounded in a Life Cycle Analysis (LCA) (Gerbinet et al., 2014). The detail of these studies can vary from simply including production all the way to the most comprehensive cradle-to-grave analysis, which will include all emissions including end of life (Vellini et al., 2017). The differences in what to include and what to exclude between studies results in a large range of values for the carbon intensity of ground mounted PV systems (from 14 to $45 \mathrm{~g}$ CO2-eq/kWh (Hernandez et al., 2014)). However, understanding of the ecosystem impacts have not been resolved.

Whilst solar PV carbon intensity studies have been limited to the quantification of technological carbon costs, there has been some attempt to also incorporate potential impacts on ecosystems for other renewable sources, such as wind (Nayak et al., 2010), and 
Biomass (Mello et al., 2014). Given the notable land take for solar parks and the potential implications for ecosystem carbon cycling, this is a critical knowledge gap.

\subsection{Aim and objectives}

The overarching aim of this paper is to develop a solar park carbon calculator (SPCC) that quantifies the technological and ecosystem carbon costs of solar parks in the UK. This could be introduced as industry guidance for best practice or as a legal requirement alongside other planning documents, to provide the planning authority with numerical suggestions of the park's impact. The four objectives are:

1. Review existing carbon calculators.

2. Determine the technological carbon costs of solar parks.

3. Evaluate the potential ecosystem carbon costs of solar parks.

4. Develop a SPCC framework suitable for use by industry.

In chapter 2 the existing literature on renewable energy carbon calculators is reviewed using a systematic approach, with any knowledge gaps identified.

In chapter 3 an idealised framework for a SPCC is provided, before carbon impacts of technological and ecosystem components are resolved for the entire lifecycle.

In chapter 4 an overarching discussion of the SPCC and its intended use is provided. 


\subsection{The Current State of Carbon Calculators}

\subsection{Introduction}

Renewable energy deployment has increased in order to mitigate climate change, with renewables set to overtake some fossil fuel sources in global energy share by 2025 (IEA, 2020). Recent emissions targets, such as the UK governments target to produce net zero carbon emissions by 2050 (GOV UK, 2019), mean that action must extend beyond carbon emissions from power plant operation. Given that renewables do not use carbon rich fossil fuels, their carbon costs are spread across their entire lifetime, including resource extraction, transport, production, installation, operation, and decommissioning (Burke and Stephens, 2018).

A Life Cycle Assessment (LCA) approach is commonly used to quantify the carbon costs of solar photovoltaics (PV) (Gerbinet et al., 2014). These studies typically focus on the emissions due to production of the technological components of a solar park, often following a cradle-tograve approach (Vellini et al., 2017). Whilst some LCAs have been undertaken for PV, the relative novelty of solar PV technology, makes literature relating to the end-of-life management relatively scarce. However, its rapid uptake and potentially significant environmental impacts have meant the EU directive on waste of electric and electronic equipment has required a suitable end of life treatment since 2012 (EU, 2018). Moreover, the means of deployment also influence emissions, with the deployment of PV as ground mounted solar parks resulting in ecosystem disturbance and thus changes in land carbon fluxes (Armstrong et al., 2016).

Carbon payback calculators may be a more encompassing approach however, as these incorporate a wide variety of carbon flows for renewable energy developments. Although solar PV has often been limited to LCA and the quantification of technological carbon costs, there has been some attempt to also incorporate potential impacts on ecosystem services and natural capital for other renewable sources, such as wind (Nayak et al., 2010), and biomass (Mello et al., 2014) through the development of carbon calculators. These studies provide evidence that it is possible to consider the carbon costs from hosting ecosystems through the construction and management of renewable energy facilities, as well as the technological carbon costs of these inputs. However, ecosystem impacts have not yet been incorporated into solar PV studies, yet studies have shown impacts on carbon cycling directly and on the local climate, a key regulator of carbon cycling (Armstrong et al., 2014; Armstrong et al., 2016).

Unlike other systems such as carbon trading however, these calculators have no robust standardised framework to follow. The differences in components considered between 
studies make direct comparisons between technologies and for different deployments of the same technology challenging. For example, the carbon intensity of ground mounted PV ranges from 10 to $80 \mathrm{~g}-\mathrm{CO} 2-\mathrm{eq} / \mathrm{kWh}_{\text {el }}$ (Leccisi et al., 2016), but some of these studies will include different boundaries (i.e. cradle to gate/grave) whilst others will include different technological setups (i.e. different types of panels). The challenge is heightened when including ecosystem carbon impacts given the dearth of knowledge in this area. However, with the need to achieve net zero, resolving the carbon costs of renewable energy technologies is important, and thus requires a robust approach to identifying necessary components of a carbon calculator.

Consequently, the overarching aim of this chapter is to identify the key components required for land-based renewable energy carbon calculators. This will be achieved by a systematic review to identify the components considered in carbon calculators for different renewable energy technologies. The findings of the review will be synthesised, and knowledge gaps identified.

\subsection{Methods}

\subsubsection{Carbon Calculator Review}

A systematic search based on QSR guidelines (Collins et al., 2015), was conducted to identify the components currently used in carbon payback calculators of different renewable energy sources. The target question posed in order to identify any existing relevant literature was "What components are present in existing carbon calculators for renewable energy sources?". The review was completed in several steps of 1 ) defining search terms, 2) performing literature search, 3) screening literature, and 4) extracting information. The scope of the study was defined to identify articles that quantified carbon flows of renewable energy sources. As the sole focus of the study was land-based renewables, the search was restricted to solar, wind, biofuels and hydroelectric. The review included papers which estimated energy payback time (EPBT), or quantified carbon flows. Firstly, the population (subject of the study) was defined as land-based renewables. However, given the breadth of terms used in the literature, the search terms were expanded to use specific renewable energy types and synonyms for renewable energy (Table 2.1). The outcome (what is achieved) of the study was defined and given the scope of the question did not include an intervention, both the intervention and control element of the QSR methodology were not relevant (Collins et al., 2015). The population and outcome strings were combined for a final search. 
Table 2.1 - Database search terms used for the systematic review

TS = Topic search; ${ }^{*}$ denotes any ending to the words.

\begin{tabular}{|l|l|}
\hline $\begin{array}{l}\text { Element of } \\
\text { the review }\end{array}$ & Search terms \\
\hline Population & $\begin{array}{l}\text { TS = ("Solar park*" OR "solar farm*" OR “wind farm*" OR } \\
\text { "biofuel*" OR "PHOTOVOLTAICS" OR "PV" OR "renewable } \\
\text { energ*" OR "green energ*" OR "renewable electricit*" OR } \\
\text { "bioenerg*" OR "low carbon electricit*" OR "low carbon } \\
\text { energ*" OR "solar tech*" OR "solar panel") }\end{array}$ \\
\hline Outcome & $\begin{array}{l}\text { TS = ("carbon calculator" OR "energy calculator" OR "carbon } \\
\text { budget" OR "carbon payback time") }\end{array}$ \\
\hline
\end{tabular}

\subsubsection{Literature search}

The search was performed on $20^{\text {th }}$ July 2020 using Web of Science's Core Collection as this consists of a rich archive of peer reviewed literature. All papers were included from 1900-2020 providing they were in English and met the search criteria defined (Table 2.1). The results were downloaded to EndNote for further sorting.

\subsubsection{Literature screening}

Publications were filtered in EndNote, first by title, then abstract and finally full text, and any papers deemed to not include relevant material were removed. At this point an additional paper (Nayak et al., 2010) was added in, as this paper did not show up in the literature search but was known to be relevant. In addition, the reference lists within the literature identified as relevant (i.e., after excluding irrelevant literature by title, abstract and full text) were searched to identify other potentially relevant studies not captured in the formal search.

\subsubsection{Information extraction}

Information from the relevant literature was compiled in a Microsoft Excel database. Specifically, paper author, renewable technology considered, location of study, and carbon stocks and flows included within the paper were extracted. The carbon stocks and flows 
reported in each paper were categorised into the six stages of renewable energy infrastructure lifecycle: Resource extraction, Transport, Production, Installation, Operation, and Decommissioning (Burke and Stephens, 2018).

\subsubsection{Information analysis}

To determine which carbon stocks and flows were of vital importance to a renewable energy carbon calculator, a tally chart was produced to demonstrate which of the components each paper had included. Definitions of inclusion for each of the components was different for each renewable given differences between renewable technologies. For example, a paper was deemed to have considered installation for solar PV if it included the emissions required to set up the panels or components, whereas for biofuels the paper could have considered emissions due to planting the crops or emissions due to setting up the processing plant.

Additional information was extracted from the papers focussing on solar PV, given their greater relevance to this study, including the type of generation technology employed, equipment required, site specifics and data sources. This review focused on qualitative analysis as it required specific details of components included, so that the strength of these could be analysed and thus included within this paper.

\subsection{Results}

\subsubsection{Overview}

In total, 106 papers were identified through the literature search, resulting in 27 relevant papers (Fig 2.1). Out of the 27 relevant papers, 18 focussed on bioenergy (10 fuel, eight biomass), four on solar PV, one on wind, one on bioplastic, one on biogas, and one on hydropower (Table 2.2, Table 2.3). In addition, there was one review paper, which focussed on multiple technologies. Across all the renewable energy technologies, sixteen papers presented a carbon payback time for the energy source, whilst the rest included at least some quantification of carbon footprint. The most frequently mentioned components of those analysed were production (24 papers) and operation (23 papers) (Table 2.2, Table 2.3), however these had different meanings for different renewable energy types. The least considered element was the end of life and decommissioning of the renewables, with only five papers including this (Table 2.2, Table 2.3). 
Figure 2.1 - represents the number of papers identified at each stage of the search and filtering process.

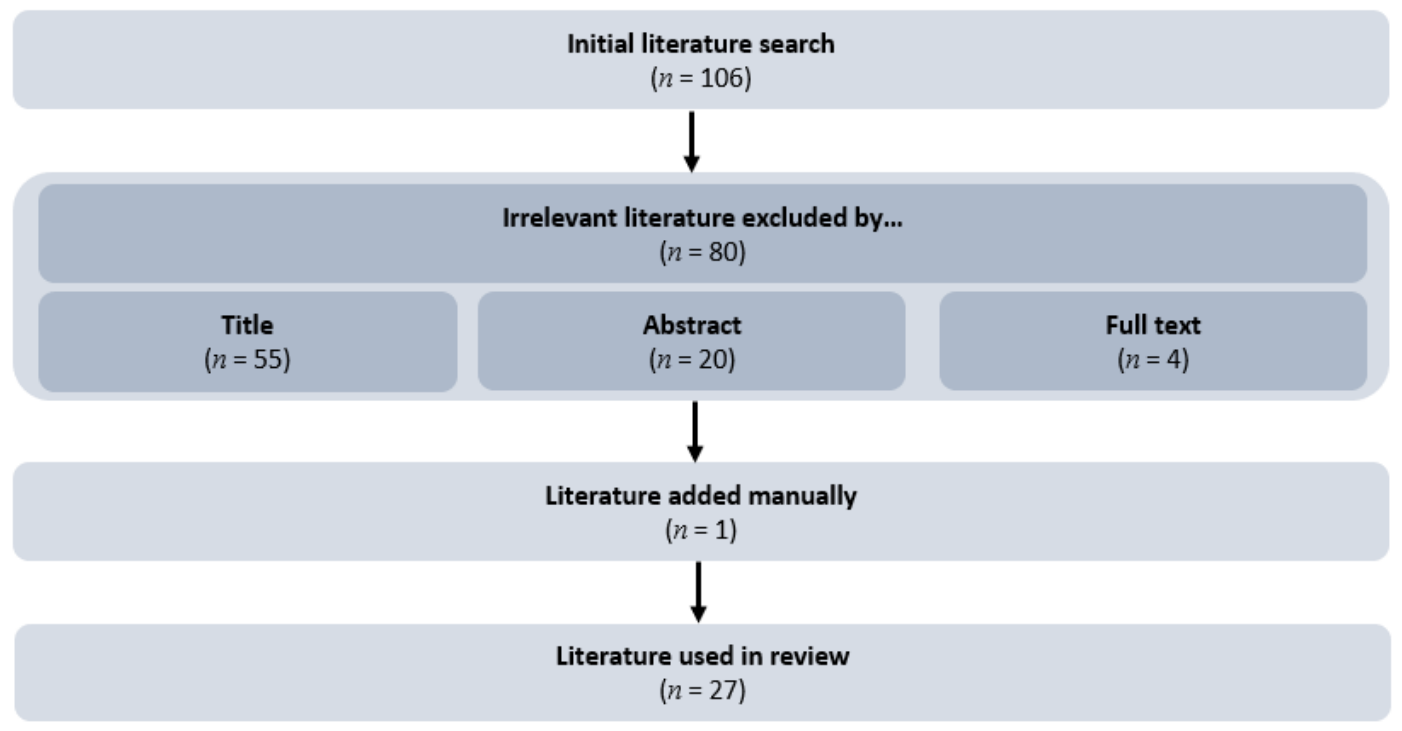


Table 2.2 - Summary of each type of renewable energy (along the columns) with the associated components (down the rows) considered according to (Burke and Stephens, 2018) framework. PV refers to Solar Photovoltaics, whilst hydro refers to Hydropower installations.

PV Biofuel Biomass Wind Bioplastic Biogas Hydro Multiple

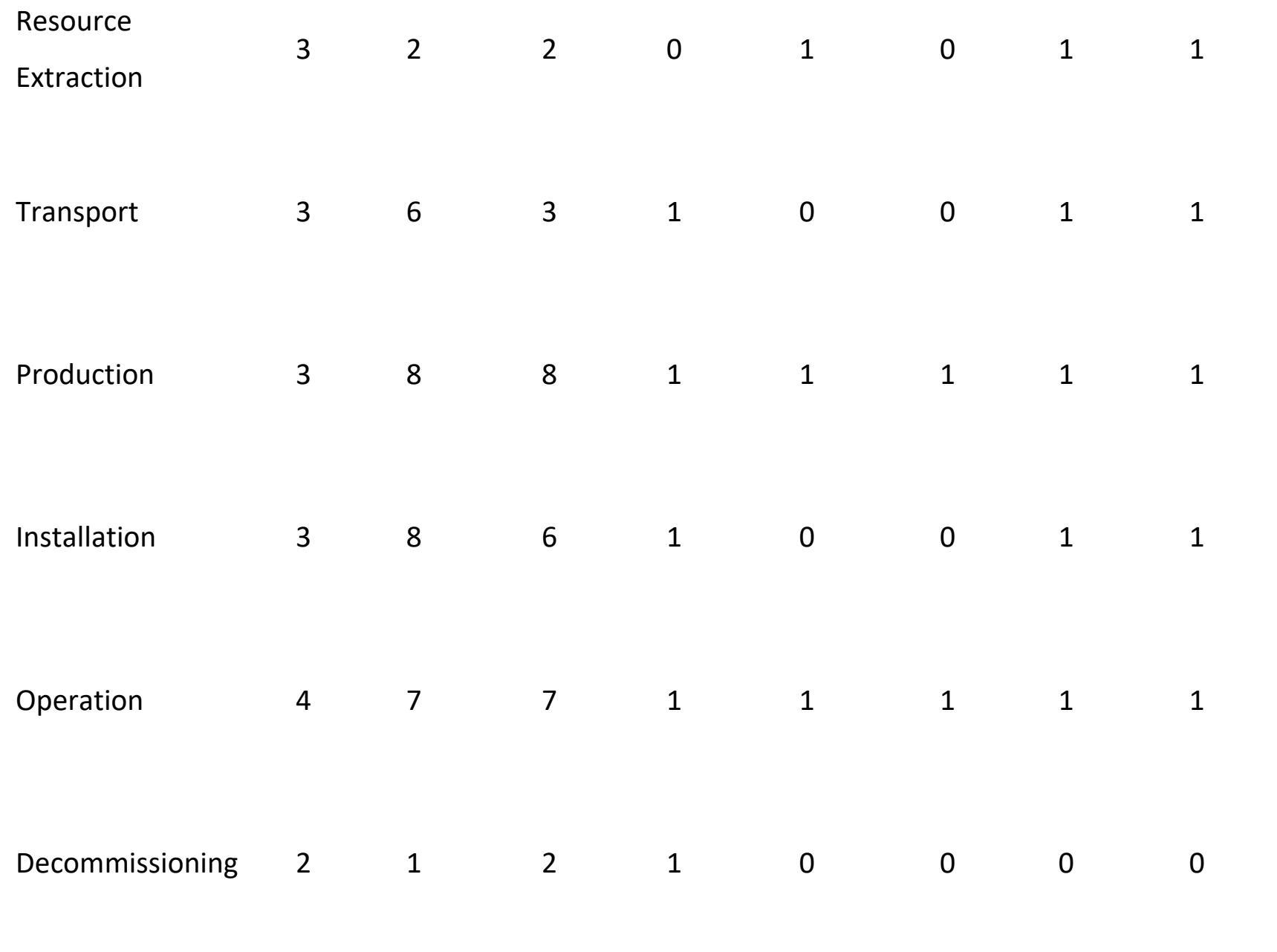

\subsubsection{Life cycle stages}

Below, evidence for each life stage presented by (Burke and Stephens, 2018) is described, across all renewable technologies. The carbon impact of the electricity produced on offsetting grid carbon intensity is also detailed. 


\subsubsection{Resource Extraction}

Resource extraction included the carbon flows related to extraction of raw materials for the production of the electricity generating technologies, or the emissions of producing chemicals for fertilisers for bioenergy studies. Resource extraction was often overlooked in many studies, with only 10 of the 27 studies detailing emissions for this lifecycle stage (Table 2.2, Table 2.3). It was more common for the more technologically reliant studies to include resource extraction emissions, with three of the four solar studies, as well as the hydropower and bioplastics studies making mention of resource extraction. Bioenergy studies generally contained very little information in the resource extraction section, with only four of the 18 studies detailing this component (Table 2.2, Table 2.3).

\subsubsection{Transport}

Transport included carbon emissions related to moving components from manufacturing site to a renewable energy facility, as well as transporting the feedstock to the processing facility and then to final users for bioenergy studies. Transport emissions were more frequently included than resource extraction emissions, with 15 of the 27 papers detailing transport components (Table 2.2, Table 2.3). Some studies based these emissions on the specific distance and shipping quantities according to site requirements (Pinto et al., 2020), whilst other studies included this as an estimate from factory to renewable site based on common practice, such as (Calciu et al., 2017) who estimated emissions of final products as $200 \mathrm{~km}$ by tanker. Some papers also considered emissions of transportation of components to recycling/waste management facilities at the end of life (Antonanzas et al., 2019), however these were included within the decommissioning section within the review.

\subsubsection{Production}

Carbon emissions related to the production phase included those derived from the manufacturing of components required for renewable energy generation, as well as any landbased carbon flows. This element was quite well considered, with 24 of the 27 papers including some mention of these carbon costs (Table 2.2, Table 2.3). Land-based carbon flows were only provided for bioenergy studies. The flows were associated with producing the main growing stage of the feedstock and factory-based emissions to process the fuel. The land-based emissions during the growing phase were related to the changes in soil and aboveground biomass carbon stored whilst the feedstock is produced (Djomo and Ceulemans, 2012). There was less focus on the emissions of producing the fuel from feedstock (Malca et al., 2011). Solar papers often considered the panels as the most significant carbon flow within this section, with (Todde et al., 2018) highlighting panels as requiring $80 \%$ of the total energy demands for development of a solar site. 


\subsubsection{Installation}

Carbon emissions related to the installation phase were those resulting from the construction/assembly of the renewable energy development and associated facilities, as well as carbon flows of initial land use change when planting the feedstock for bioenergy studies. This mostly referred to machinery emissions required to set up the facility for technological dependent facilities such as solar (Todde et al., 2018). Bioenergy studies frequently included carbon flows from initial land use change of planting feedstocks (Djomo and Ceulemans, 2012), yet the emissions of making the facility were less commonly included (Souza et al., 2012).

\subsubsection{Operation}

Carbon emissions from operation included any emissions associated with the production of energy (electricity or otherwise) from the renewable source, as well as any emissions due to maintenance. For facilities such as solar that do not produce emissions during electricity generation, this is limited to maintenance emissions. Pinto et al. (2020) assumed that $6.7 \%$ of electricity will be required for the operation of a solar park. For bioenergy studies, this was often presented as the emissions of using the fuel produced (Calciu et al., 2017), with few papers considering maintenance of equipment (Souza et al., 2012).

\subsubsection{Decommissioning}

Decommissioning carbon flows include emissions from shutting down renewable facilities and managing any waste materials, including negative emissions for any materials recycled. This also includes any land-based carbon flows of returning to original land use for bioenergy studies that required growth of a feedstock. Two of the four solar papers (Todde et al., 2018; Antonanzas et al., 2019) included information regarding the end of life of the solar parks (Table 2.2, Table 2.3), both of which highlighted negative emissions associated with recycling of materials. Two biofuel (Gibbs et al., 2008; Pacca and Moreira, 2009) and two biomass (Marland and Schlamadinger, 1995; Matthews, 2001) studies included emissions related to decommissioning (Table 2.2, Table 2.3). However, these were mostly related to the land use change of returning land to pre-feedstock use. Nayak et al. (2010) was the only non-bioenergy paper to consider the land use impacts of decommissioning a renewable energy development (Table 2.2, Table 2.3), mentioning carbon benefits of restoring peatlands after decommissioning.

\subsubsection{Energy offset}

Energy offset refers to the carbon savings from producing energy via renewable sources, as compared to the same amount of energy produced by the national grid, which has a notable component of carbon-rich fossil fuel sources. This was a regular component in the literature; 
however, the type of renewable determined the carbon savings demonstrated. For example, the carbon savings for wind power referred to the emissions that would have occurred producing the same amount of electricity from the grid mix (Nayak et al., 2010). A similar process was followed for some solar carbon calculators (Antonanzas et al., 2019; Pinto et al., 2020). However, biofuel savings were often presented as the reduction in fossil fuels (petrol/diesel) required due to the availability of this source (Djomo and Ceulemans, 2012). A similar approach was seen for biomass studies, but this was often for the offset of coal (Jonker et al., 2014), or combined heat and power (Peckham and Gower, 2013). 
Table 2.3 - Results of the literature search showing renewable energy sources separated by colour. Each corresponding row signifies a paper and a tick in the column indicates the inclusion of that component within the study (e.g., resource extraction). A '?' signifies this component was included but was vague as to how it was quantified or aggregated with other components so that it was impossible to discover the independent influence of this factor. Due to their particular relevance - solar papers are shaded on a gradient, with darker shading of each box denoting the higher relative importance of each of the life cycle stages on carbon flows and stocks.

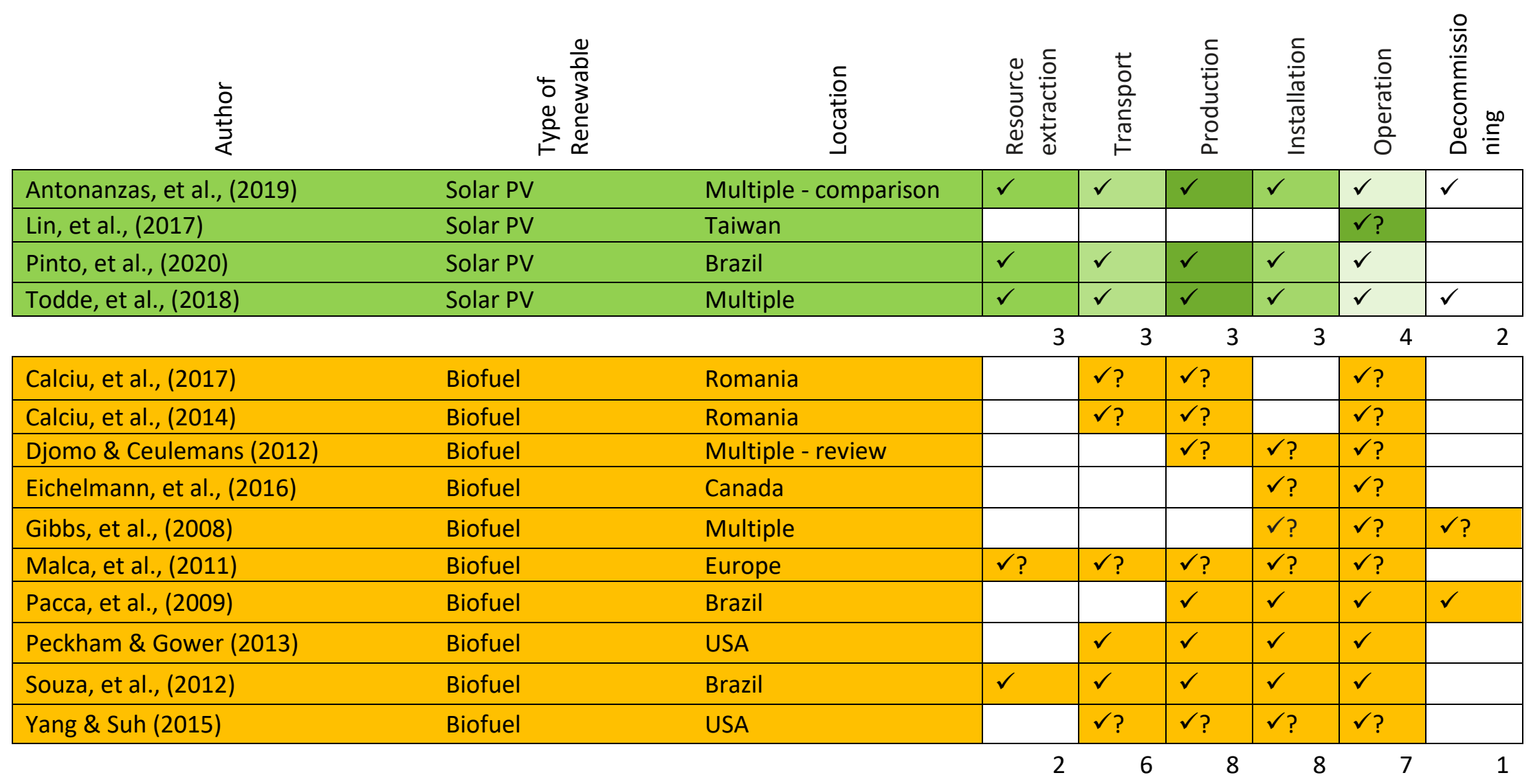




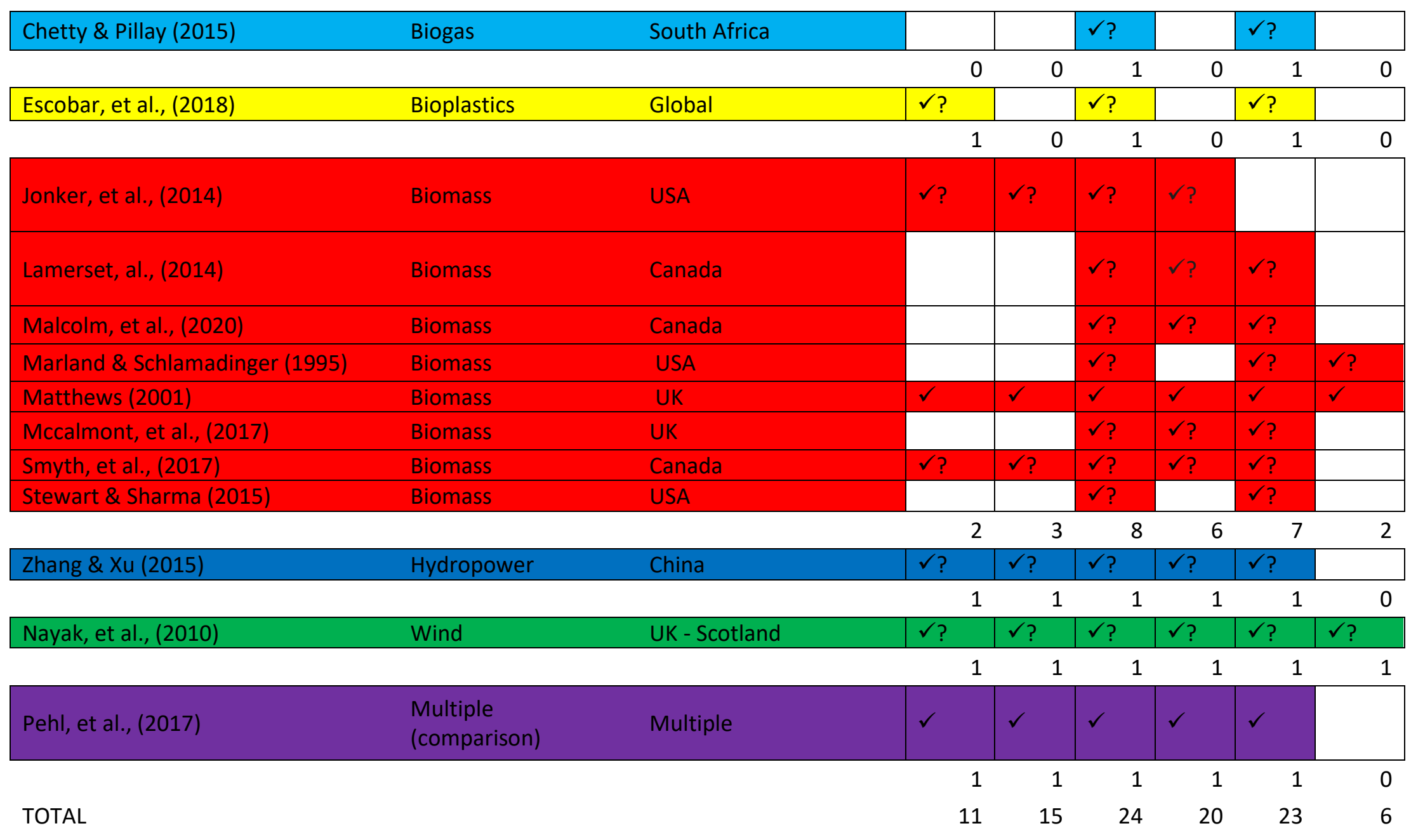




\subsection{Discussion}

Despite the importance of minimising the carbon intensity of renewable energy technologies, comprehensively capturing effects from cradle to grave is rarely done (Vellini et al., 2017). Moreover, ecosystem impacts are rarely included, yet these are pivotal given net zero targets and legal commitments across the world. Moreover, the carbon costs need to be contextualised with the current grid carbon intensity. Discussion of the carbon flows for all lifecycle stages, including understanding of these can be improved through separation into subsequent parts and consideration of spatial dynamics is included below.

\subsubsection{Separation of carbon flows in all lifecycle stages}

Results have been presented according to the six lifecycle stages of a solar park indicated by (Burke and Stephens, 2018) as this assures a comprehensive assessment. However, it became apparent that the use of this structure is made challenging by the presentation of information in current calculators. For example, it was often unclear as to whether resource extraction had been included within a paper; often production emissions were calculated, but it was not clearly demonstrated as to whether this included the extraction of raw materials or simply the manufacture of the infrastructure. For example, (Nayak et al., 2010) included aggregated emissions data within "infrastructural overhead". Identifying the finer scale emissions is vital in order to reduce overall carbon emissions.

\subsubsection{Improving understanding of ecosystem carbon impacts}

Understanding ecosystem carbon impacts of renewable energy technologies is important to reach net zero commitments. However, although the ecosystem impacts of bioenergy technologies are relatively well resolved, this is not the case for the majority of other renewable sources. However, there is one example of ecosystem impacts for wind (Nayak et al., 2010) and hydropower (Zhang and $X u, 2015)$. The wind study detailed the carbon impacts of wind farms caused by disturbing carbon rich peatland soils, whilst the hydropower study examined the impacts of soil erosion and habitat destruction caused by hydroelectric dams. In addition to understanding the ecosystem carbon impacts, capturing impacts on ecosystems, including goods and services and natural capital more generally is critical to ensure the sustainable deployment of renewables (DEFRA, 2020). Given the role of carbon, failure to include information regarding the ecosystem carbon impacts of a renewable energy development could result in a failure to realise the potential benefits to ecosystem services and natural capital that can be achieved through best practice, such as the soil quality 
improvements experienced by employing grazing in place of mowing (Randle-Boggis et al., 2020).

Different ecosystem impacts can manifest for different technologies. Solar developments are subject to shading by panels, which can lead to up to a $75 \%$ reduction in aboveground biomass growth (Armstrong et al., 2016). Dams for hydroelectric installations can cause significant $\mathrm{CH}_{4}$ emissions due to stagnant water (Pehl et al., 2017), whilst wind turbines can require drainage of peatlands leading to carbon emissions (Nayak et al., 2010) and create localised differences in temperatures (Armstrong et al., 2014). However, these impacts have not been well resolved and understanding only exists for a limited number of sites.

Land management and land use change can result in carbon impacts on different ecosystems. Randle-Boggis et al. (2020) highlight how solar parks can be managed using practices such as grazing and reseeding to bring benefits for ecosystem services and natural capital. Guerin (2017) mentions the inclusion of buffer areas in solar parks to reduce incidence of soil erosion and thus associated carbon losses, and (Hernandez et al., 2014) also discusses fibre production as a method of achieving this. Alternatively, wind installations can experience habitat improvement due to management, reducing carbon impacts through peatland restoration and returning native species (Nayak et al., 2010). The inclusion of these aspects can work to strengthen the reliability of estimates provided by current carbon calculators.

\subsubsection{Advancing understanding of decommissioning carbon stocks and flows}

In general, the end-of-life emissions were poorly resolved within the renewable energy calculators, with only five of the 27 papers reviewed including this information. Out of the energy sources, solar was the best for including this information, with two of the four papers including decommissioning data (Todde et al., 2018; Antonanzas et al., 2019). Problems may arise if the end-of-life emissions of renewable energy developments are not considered, as there may be significant carbon impacts that are missed in this stage. This is particularly significant if the site has large capital carbon costs, that cannot be recovered through recycling, especially if materials have toxic properties (Vellini et al., 2017). Consequently, renewable energy carbon calculators should aim to include at least some discussion of the impacts of the end-of-life process. For solar, inclusion could significantly reduce overall emissions if equipment is recycled, given the high proportion of emissions associated with the manufacturing of equipment (Todde et al., 2018). However, due to the majority of solar PV projects taking place in recent years, the lack of facilities reaching their decommissioning stage 
may mean that this information is hard to come by or does not yet exist. There is potential that estimates for end-of-life emissions will be higher than the actual emissions as the move towards solar brings increased potential for better recycling practices.

\subsubsection{Incorporating temporal dynamics}

Even though a dynamic temporal aspect was only included in two of the 27 papers reviewed to develop this calculator (Djomo and Ceulemans, 2012; Yang and Suh, 2015), inclusion of a temporal aspect could be very useful for renewable energy carbon calculators. This could not only make projections for natural carbon flows more realistic (providing the ability to capture different accumulation rates for natural processes), but this also allows for improvements in technology which have already been seen over recent years. This would also allow for discounting of future emissions savings if desired as the user would be able to place different weightings on emissions depending on time of release. This was highlighted by (Yang and Suh, 2015) and has been a common practice in financial modelling for many years, representing the value of money today is higher than tomorrow. This same approach can be applied to demonstrate that taking action to reduce emissions now will be more effective than future efforts.

\subsection{Conclusions}

In order to achieve net zero emissions targets, without unintended consequences to ecosystem services and natural capital, an understanding of both the technological and ecosystem carbon stocks and flows of renewable energy sites is required. Given the growth in solar parks, associated land use change, and environmental targets, a solar park carbon calculator (SPCC) could be influential in minimising carbon cost of renewable energy. However, the lack of a standardised approach, has meant current carbon calculators often fail to quantify the full suite of impacts. This systematic review has highlighted that current solar carbon calculators focus almost exclusively on the technological carbon impacts, using a LifeCycle Assessment approach. However, ecosystem carbon impacts have been incorporated for other technologies. Across the range of technologies only a few studies attempt to capture both of technological and ecological impacts. A SPCC should incorporate all carbon flows, from construction through to operation and finally decommissioning, of the development lifecycle, as well as the carbon intensity of alternative energy generation. Both technological carbon flows - highlighting emissions due to producing components and machinery usage - and 
ecosystem carbon flows - highlighting land use change and management carbon flows - are vital components for such a tool. Without developing such a tool, there is a risk that the carbon intensity of the electricity produced will be higher than possible, with impacts for net zero targets. 


\subsection{Development of a Solar Park Carbon Calculator}

\subsection{Rationale}

In recent years, there has been increased awareness in policymaking to reduce carbon emissions, with global efforts (e.g., the Paris agreement) legally binding signatory countries to comply with emissions targets (UNFCCC, 2015). Increasingly, this has moved towards the concept of net zero emissions, with the UK Government announcing a legal commitment to 'offset' carbon emissions by 2050 (GOV UK, 2019). Plans to achieve this include the decarbonisation of energy systems and an increasing in natural carbon sinks (DEFRA, 2020). The expansion of renewable energy technologies will be essential for decarbonising energy supplies. However, efforts to sequester carbon in natural sinks could be hindered by the effects of land use change for renewable infrastructure (Armstrong et al., 2016). It is therefore vitally important to quantify a full range of carbon flows from renewable energy systems to estimate the true carbon cost of the electricity produced.

The recent rapid uptake of solar PV, combined with future projections, indicate a notable increase in PV capacity around the world by 2050 (IEA, 2019). Moreover, whilst it varies between nations, a notable proportion has been, and is expected to be, deployed as solar parks due to economies of scale. This, combined with the much lower energy density of this technology (solar PV requires $>10$ times of land than coal per TWh electricity produced; (Gagnon et al., 2002), has led to a significant increase in land use change for solar parks around the world. Although it has been highlighted that land use change is a greater threat to nature than climate change (IPBES, 2019), the associated ecosystem impacts of solar PV coverage are currently not well resolved. This lack of knowledge could be due to the relative novelty of the technology, with a recent rapid shift to ground-mounted systems as opposed to roof-mounted installations, which do not result in the same environmental impacts. However, recent efforts highlight impacts on microclimate and aboveground biomass productivity (Armstrong et al., 2016), as well as suggestions as to how they can be managed to provide environmental benefits, including for ecosystem carbon sequestration (Hernandez et al., 2019; Randle-Boggis et al., 2020).

Despite the importance of understanding the carbon intensity of renewable energy technologies, including the ecosystem carbon costs as a result of the accompanying land use change, there are limited carbon calculators for solar PV. Likely driven by knowledge gaps in the ecosystem impacts of solar parks (Armstrong et al., 2016), the focus of existing carbon calculators has largely been on the technological aspects of new developments, with Todde et 
al. (2018) suggesting that $80 \%$ of the energy input to a solar development could be attributed to module production (Chapter 2). Currently, no solar carbon calculators for solar PV mention associated environmental carbon flows (Chapter 2), although some carbon calculators for other technologies (e.g., wind) include ecosystem carbon costs (Chapter 2). For example, Nayak et al. (2010) explore not only the carbon impacts of the technology used to construct wind farms, but also the potential impacts to carbon cycling in the hosting peatland caused by their development. Zhang and Xu (2015) also consider the potential ecosystem impacts, including soil erosion due to hydroelectric dams. In addition, environmental carbon costs are commonly incorporated into biofuel carbon calculators, with the feedstock production contributing a significant amount to the overall environmental impacts of the fuel (Chapter 2).

Consequently, to develop a wholistic renewable energy carbon calculator, both technological and ecosystem carbon stocks and flows throughout the life-cycle -resource extraction, transport, production, installation, operation, and decommissioning (Burke and Stephens, 2018) - need to be captured. However, difficulty in identifying finer scale information within these lifecycle stages, as highlighted in (Chapter 2), mean the focus has been on the construction, operation, and decommissioning stages of renewable energy developments, as these could more effectively incorporate the carbon costs found in the current literature.

Carbon stocks and flows included in the construction of a solar park refer to any carbon costs associated with the development of a solar park. These include manufacture and acquisition of all components required for a functioning solar park for the duration of its lifetime (including spares that are purchased in advance), any construction activities and associated machinery or materials required, as well as any disturbance to the natural landscape. Operational carbon costs refer to carbon stocks and flows that occur during the designated operational "lifetime" of a solar park. These include the offset electricity due to production by the solar park, impact of the solar park infrastructure on the hosting land, environmental management of the area within the solar park and any machinery use associated with the replacement of any components. The majority of additional replacement parts/materials are commonly purchased during the construction phase and thus are included in that phase. However, some unexpected needs may occur post construction and they will be included in the operational stage. Decommissioning carbon costs refer to carbon stocks and flows associated with the end of life of a solar park. These will include removal and disposal of any infrastructural components of the solar park, any construction-based activities required to clear the land and any changes to the management of the land. Although some components will become obsolete during the operational phase of the solar park and require replacement, 
the disposal of these components are considered along with any other components in the decommissioning phase.

The vital importance of decarbonising energy supplies, whilst avoiding release of ecosystem carbon and ideally enhancing ecosystem carbon sequestration, demands a wholistic analysis of the lifecycle carbon impacts. This knowledge is critical for solar parks given their anticipated deployment rates and high land take. Consequently, the overarching aim of this chapter is to devise a Solar Park Carbon Calculator (SPCC) that quantifies technological and ecosystem carbon costs throughout the lifecycle of a solar park. This will be achieved through a number of objectives: (1) development of an idealised SPCC framework, (2) resolution of the carbon stocks and flows for each of the lifecycle stages. The strengths and weaknesses of the approach adopted here, as well as future research needs, are outlined in the Discussion.

\subsection{Methods}

Developing the SPCC required two components: an idealised framework, and the resolution of carbon stocks and flows. The methods for each are detailed below.

\subsubsection{Idealised SPCC framework development}

\subsubsection{Knowledge base}

The development of an idealised SPCC framework was based on both academic understanding and stakeholder expertise. Firstly, the systematic review completed in Chapter 2 was used to identify key components of an SPCC. Briefly, a systematic review was undertaken and all carbon stocks and flows extracted and categorised by life cycle stage (Burke and Stephens, 2018). The solar calculators were analysed in more detail to identify carbon stocks and flows relevant to solar parks. The focus of the four solar-related studies on LCA of the technological aspects of a solar park highlighted the significant emissions that would be attributed to these, underlining they were vital for inclusion within the SPCC. These included factors such as the manufacture and transport of equipment to the site, electricity generated during operation and the management of equipment at the end of life. In addition, the bioenergy papers and the Nayak et al. (2010) wind energy calculator were used to identify potential ecosystem carbon flows associated with solar parks and land use change, given the omission of these components in the majority of renewable energy carbon calculators. The analysis of these emissions and savings would provide the carbon payback time of the installation in question, further demonstrating the suitability of the solar park to act as a net carbon sink. 
After a suite of carbon stocks and flows has been identified from the academic literature, stakeholders were consulted to glean specific information. The aim of this was to improve the usability of the SPCC and reduce uncertainty in the outcomes. Knowledge gaps were identified within the existing literature in terms of new technologies, construction methods and UK specific conditions (e.g., types of former land use). Discussions were held via Microsoft Teams between late 2020 and early 2021 with a number of industry professionals from all areas of the development process, including those negotiating for landowners and project designers. These meetings enabled the collation of a wide array of expertise and identification of additional useful contacts and relevant industry documents. Ultimately, this information was critical to ensure the end product SPCC meets industry needs and reflects the current practices of solar park developments.

\subsubsection{SPCC terminology}

In order to allow for easy comparison between results, as well as standardising the inputs, the SPCC makes use of both reference flows and functional units (Frischknecht et al., 2015). A reference flow refers to the criteria for which impacts of the system being studied are quantified against Frischknecht et al. (2015). Although material emissions and land take of solar parks have been diminishing over time (Solar Trade Association, 2019; Szilágyi and Gróf, 2020), the size of a solar park development has a positive correlation with the emissions it will generate. Therefore, the SPCC uses one kW as a reference flow, so that carbon impacts are quantified based on the nameplate capacity of the solar park. According to (Frischknecht et al., 2015), "the functional unit determines the quantified performance of a product system", with one kWh of AC power supplied to the grid chosen as a functional unit. The use of a functional unit allows the electrical output to be compared with different technologies (PV vs grid mix) (Frischknecht et al., 2015), thus providing evidence for the negative emissions due to generation.

With the exception of the 'Environmental Calculations', 'Payback Time' and 'Tech Calculations (Generic)' sheets, throughout the SPCC, the user is provided with space to input their own actual value, or given the option to use a suggested value based on the information presented within Table 3.1. Whilst using actual values (i.e., carbon costs of a specific PV panel) will increase the accuracy of the SPCC estimates, providing a suggested value assures the SPCC can still be used if certain values are not available to the user. A generic approach is also provided as an additional section of the SPCC - within the 'Tech Calculations (Generic)' sheet - to estimate the entirety of technological carbon flows when information is lacking. The sources 
for this approach can be found in Table 3.2. From here on out, 'actual' values are those the user provides to the SPCC based on site specific information, 'suggested' values are those provided by the SPCC to the user to be used at their own discretion, and 'generic' values are the estimates of the total technological carbon flows as per 'Tech Calculations (Generic)' section of the SPCC.

The generic approach is only provided for technological costs because ecosystem costs are mostly provided to the user by the SPCC given the paucity of data in this area, although these outcomes rely on site specific details, such as size and previous land use, which are entered by the user. Additionally, discussions with developers highlighted that specific technological components (e.g., PV panels) of the solar park may not be decided upon until later into the planning process. Therefore, the generic approach allows the user to select a predefined value for technological emissions. For example, the user can select the type of panels based on the de Wild-Scholten (2013) or Jinko JinkoSolar (2018) solar averages, rather than the specific brand, to provide a value for the emissions of panels. Emissions for all other Balance of Systems (BOS) components are then based on Mason et al. (2006), which provides an estimate of emissions for all technological components of a solar park (including construction, operation and decommissioning). For example, this study was referenced in the Life Cycle Inventories and Life Cycle Assessments of Photovoltaic Systems 2020 (Frischknecht et al., 2020) among other recent studies, suggesting it is still considered a reliable estimate. Although preference should be given to more recent or UK-based studies, no suitable data were found.

\subsubsection{Resolution of carbon stocks and flows}

Values for the stocks and flows of carbon identified in Objective 1 were compiled from the academic literature, reputable industry reports, and existing environmental data sets. Up to date academic journal articles and industry reports were used to gather insight into the requirements of specific components per kW solar park capacity and the emissions attributed to the manufacturing of these components (full details are given in Table 3.1). These sources were found through internet searches, sources identified in the articles used to meet Objective 1 and recommendations from industry.

In order to assess the impacts of land use change for solar parks, a database of 1,032 UK solar parks with digitised shapefiles and associated capacities, was used. Average solar park area and average area under the solar panel arrays per MW were determined based on the average areas of the full 1,032 digitised solar parks, divided by their installed capacity, with the same 
process followed for perimeter values. Averages for land use change due to access tracks and other infrastructure (e.g., transformers, inverters, energy storage units, DNO substations and customer substations), were derived from a sample of 50 solar parks, randomly selected from the full range of the digitised solar parks. Land coverage of access tracks and buildings were measured in ArcGIS Pro before being combined with average land coverage to derive percentage land coverage (see appendix for more details).

Most of the data were converted to standard units. Soil carbon stocks were extracted from the National Soils Inventory (NSI) Land-IS NATMAP Carbon and the UKCEH 2019 Land Cover Map (LCM) 25 m raster (Morton et al., 2020) datasets using ArcGIS Pro. The NATMAP average soil carbon data at 0-30 cm, 30-100 cm and 100-150 cm were imported and converted into a raster using the feature to raster tool. The zonal statistics tool was then used to produce the average soil carbon value for each of the 21 categories in the UKCEH LCM for each soil depth. The average soil carbon $\left(\mathrm{kg} \mathrm{m}^{2}\right)$ for each of the 21 land cover classes was calculated for each of the soil depths $(0-30 \mathrm{~cm}, 30-100 \mathrm{~cm}$, and 100-150 cm). Results were exported into an Excel document and the total soil carbon stocks were calculated by adding the concentrations for all three soil depths resulting in the average soil carbon, in units of tonnes/ha, for each land cover class. These values were compared to the CEH countryside survey data (Emmett et al., 2010) and Bradley (2005) to determine accuracy. These data were then used to estimate soil carbon stocks, by multiplying the area in question by the average soil carbon value for that land use type.

A solar park may impact aboveground carbon stocks due to vegetation management strategies and affect vegetation growth rates due to changes in microclimate (Hernandez et al., 2014; Armstrong et al., 2016). Consequently, aboveground carbon stocks were estimated, based on figures within Milne and Brown (1997), to include the aboveground biomass per ha for a number of land use types. To account for the impact of changes in microclimate caused by the solar arrays on the aboveground biomass, these values were multiplied by 0.25 (Armstrong et al., 2016). 
Table 3.1 Components quantified within the SPCC and the sources for the suggested values associated with these. No suggested value is included in the SPCC for components that are stated as specified by user.

\section{Component}

\section{Information Acquired \& Source}

\section{Technological}

Panel Emissions

Average emissions Europe/China - (de Wild-Scholten, 2013), Jinko Solar - (JinkoSolar, 2018)

Mount Emissions

Average Steel requirements - (ArcelorMittal, ND), Average

Steel emissions - (ICE, 2019)

Cabling Emissions

Average cabling requirements per kW - (Mason et al., 2006)

Inverter Emissions

Germany vs ROW inverter emissions - (SMA, 2018)

Switchgear/Transformers

Specified by user

emissions

Fencing Emissions

Average fencing area - (unpublished data), Average steel requirements - (First Fence, ND), Average Steel emissions (ICE, 2019)

Other Raw materials Average emissions per tonne required for: Concrete, Steel, emissions Aluminium, Glass, Copper \& PVC (ICE, 2019).

Transportation Emissions

Average emissions of different transportation methods - (Time for Change, ND),

Machinery Use Emissions

Specified by user

\section{Ecosystem}

Soil carbon quantities

Soil carbon stocks (Land IS NATMAP carbon), Land use map (Morton et al., 2020)

Aboveground biomass Average aboveground biomass per ha - (Milne and Brown, carbon 1997)

Average Solar Park

Average Solar Park coverage per kW (unpublished data) coverage

Average Complete Average coverage for access tracks per kW - (unpublished coverage data), Average coverage for buildings per kW - (unpublished data) 


\section{Electricity}

Electricity generated

DUKES Capacity Factor - (GOV UK, 2020)

Generation emissions

UK grid emissions factor (Electricity Info, ND) or emissions over

offset

time (DECC, 2019)

Table 3.2 Information provided within the generic approach to technological emissions within the SPCC.

\section{Component Information acquired \& Source}

\section{Technological Generic Approach}

Panels

Balance of System (BOS)
EU vs Chinese production - (de Wild-Scholten, 2013), Jinko Average - (JinkoSolar, 2018) BOS emissions per kW for ground mounted PV facility - (Mason et al., 2006)

\subsection{Results}

Below, the idealised overarching framework is detailed (Objective 1), followed by a summary of how each of the carbon stocks and flows were estimated (Objective 2), and finally an application of the SPCC to a case study solar park is provided (Objective 3).

\subsubsection{Idealised SPCC Framework}

Grounded in academic literature and stakeholder insight, the idealised SPCC framework comprises 16 technological components, with four related to construction, eight to operation and four to decommissioning (Figure 3.1). Estimates with the highest levels of confidence belong to the construction and operational phases, with highest certainty around the manufacture of components and generation of electricity, due to the focus of previous solar LCA studies in these areas (Chapter 2). 
In comparison, there are 12 ecosystem components, with two related to construction, seven to operation and three to decommissioning (Figure 3.1). Given the lack of existing studies on the ecosystem carbon effects of solar parks, there is much lower certainty with these components and thus it is not possible to infer likely scale of impact of each of the components. 


\begin{tabular}{|l|}
\hline Construction \\
- Manufacture of components \\
- Machinery emissions during construction \\
- $\quad$ Additional resource use during \\
construction (e.g., water, data-use) \\
Components: panels, mounts, cabling, inverters, \\
switchgear/transformers, fencing and other raw \\
materials. \\
\hline Ecosystem: \\
- Impacts on \\
- Soil C \\
Due to: Complete coverage - (Access tracks, \\
Transformers, Inverters, Energy Storage units, \\
DNO Substation, Customer Substation, \\
Construction compound), Construction \\
impacts (Ground compaction, Soil erosion \\
(wind/water), Trenching - Cables) \& Land \\
cover change \\
\hline
\end{tabular}

\begin{tabular}{||l||}
\hline \multicolumn{1}{|c||}{ Operation } \\
\hline - Electricity generated/offset \\
- Backup generation \\
- Manufacture of replacement components \\
- Machinery use for maintenance. \\
- - Enanagement, replacing components. \\
- Tracking use during operation \\
- Lighting \\
\hline
\end{tabular}

Ecosystem:

- Perturbations to

- Soil C

- Aboveground biomass

Due to altered microclimate, soil erosion, disturbance during construction including compaction.

- Management interventions

- Mechanisms to enhance Biodiversity.

- Mowing/Grazing

- Seeding

- Nutrient addition

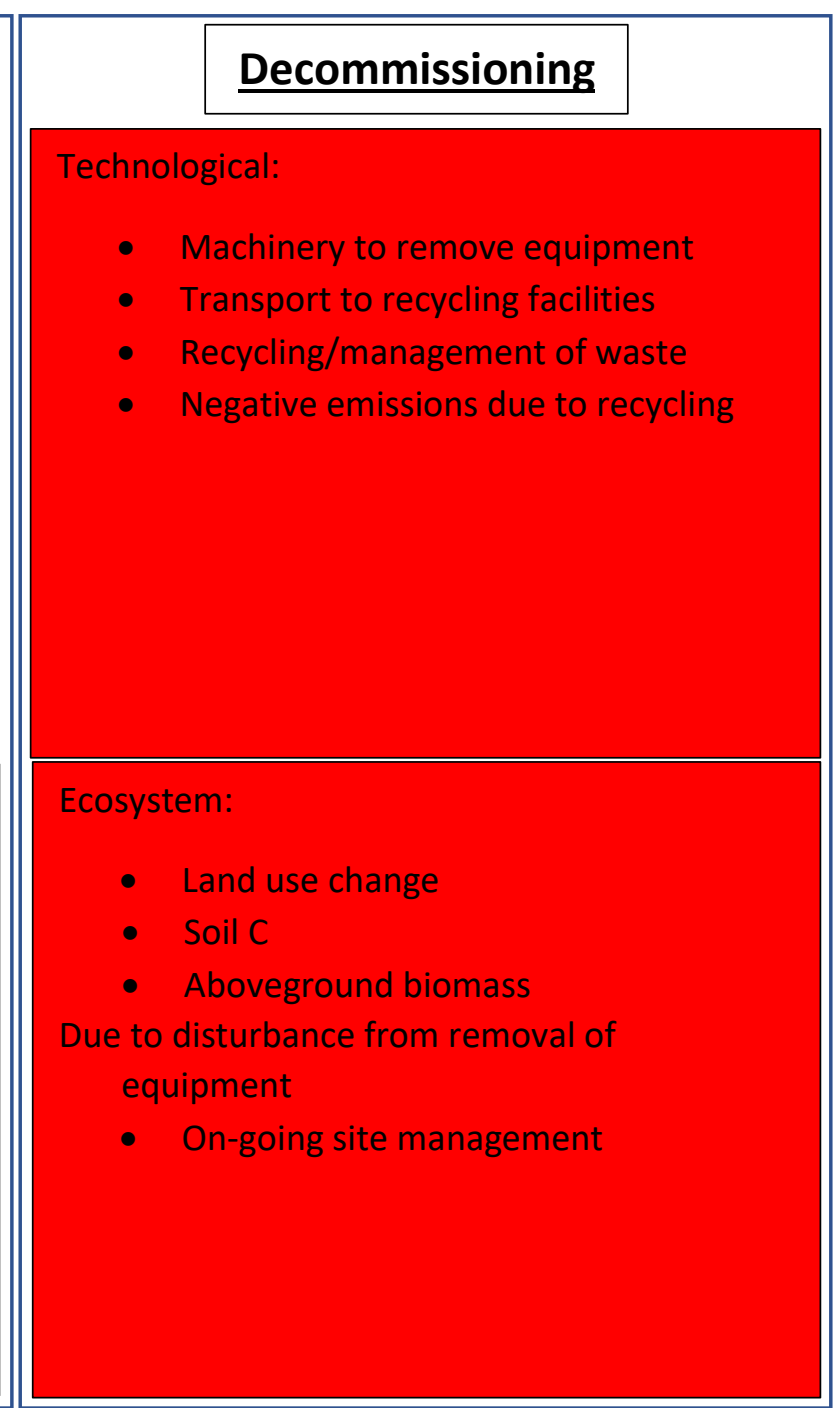

Figure 3.1 Visual representation of the idealised SPCC framework, highlighting the important elements for an SPCC within the context of the construction, operation and decommissioning phases and the likely technological and ecosystem carbon impacts within these phases. The colouring of each box follows a traffic light system according to the current certainty about the associated carbon flows, with green indicating higher certainty, yellow medium certainty and red low certainty. 


\subsubsection{Resolution of carbon stocks and flows}

Within this section, each of the technological and ecosystem components within the construction, operation and decommissioning stages outlined in the idealised SPCC framework are defined. These draw on a wide range of data sources (Table 3.1).

\subsubsection{Construction - Technological}

\subsubsection{Manufacturing of components}

Construction carbon costs are largely focussed on the manufacturing of components needed in a solar park, including panels, mounts, cabling, inverters, transformers/switchgear and fencing (Frischknecht et al., 2016) and additional materials (e.g., concrete, glass, copper) (Eq. 1). Components other than panels are often grouped under the broad category of the BOS of a solar park (Mason et al., 2006), but to improve accuracy of the SPCC estimates, these are separated out. These estimates also include carbon emissions relating to resource extraction.

$$
C_{\text {Man }}=C_{\text {Panel }}+C_{\text {Mount }}+C_{\text {Cable }}+C_{\text {Invert }}+C_{\text {Switch }}+C_{\text {Fence }}+C_{\text {Add }} \text { (Eq 1) }
$$

\subsection{Panels:}

Panels are the greatest contributor to manufacturing carbon emissions. Emission estimates in the calculator were computed based on a simple equation Eq. 2:

$$
C_{\text {Panel }}=\left(k W * C E_{\text {panel }}\right) / 44 * 12(\mathrm{Eq} \mathrm{2})
$$

With $\mathrm{C}_{\text {Panel }}$ (tonnes carbon) as the total carbon flow associated with panel production, $\mathrm{kW}$ representing the nameplate capacity of the solar park (defined by the user) and $\mathrm{CE}_{\text {panel }}$ (tonnes $\mathrm{CO}_{2}$ ) representing the $\mathrm{CO}_{2}$ emissions resulting from production of $1 \mathrm{~kW}$ of panels. The correction at the end $\left(/ 44^{*} 12\right)$ converts from $\mathrm{CO}_{2}$, as emissions are commonly provided in this unit, to carbon.

Within the SPCC, users are encouraged to input their own actual values for $\mathrm{CE}_{\text {panel, }}$, based upon the specific panels installed at their solar park. This information should be provided in the manufacturer's fact sheet. When this information is not available, users are able to input a suggested emissions value sourced from the literature. The majority of this information was obtained from de Wild-Scholten (2013); specifically emissions for Mono-Si, Multi-Si, a-Si, CdTe and $\mathrm{CIGS}$ under both EU and Chinese grid mixes and $\mu \mathrm{m}$-Si under EU grid mix only. In addition, Jinko's (2019) solar environmental report was used to obtain additional information of the average emissions per kW of panels produced in all their manufacturing sites (industry 
professionals highlighted that information from top suppliers to utility developments would be reliable and Jinko solar is constantly ranked within the top suppliers of panels).

\subsection{Mounts:}

Industry expertise highlighted that the overwhelming majority of panel mounting structures in UK solar parks are non-tracking, piledriven steel mounting structures. As a result, the SPCC manufacturing carbon costs are based on this style of mounting structure, with the implications of other mounting systems outlined in the Discussion. Where possible, the emissions from mounting structures should be determined from the manufacturer fact sheet, as this allows for the user to generate the most accurate emissions with use of Eq. 3:

$$
C_{\text {Mount }}=\left(\boldsymbol{k W} * C E_{\text {Mount }}\right) / 44 * 12(\mathrm{Eq} 3)
$$

Where $\mathrm{C}_{\text {Mount }}$ (tonnes carbon) is the total carbon flow associated with mount production and $\mathrm{CE}_{\text {mount }}$ (tonnes $\mathrm{CO}_{2}$ ) represents the $\mathrm{CO}_{2}$ emissions resulting from production of mounting structures required for one $\mathrm{kW}$ of solar park.

However, in situations where the user has not been provided with a fact sheet from the manufacturer, there is an option to use a suggested value, which makes a suitable estimate based on emissions per $\mathrm{kg}$ of steel produced. Due to an increase in emissions reporting, the average emissions of steel production per tonne are readily available. If the weight of steel used is not available to the user, ArcelorMittal (ND) report that each MW of solar power requires between 35 to 45 tons of steel (35-40 kg per $\mathrm{kW}$ ), with the majority of this for the mounting structures. Consequently, the total weight of steel required can easily be estimated by multiplying this by the nameplate capacity. Furthermore, this can then be multiplied by the average emissions for producing one tonne of steel, specified as 1.55 tonnes of $\mathrm{CO}_{2}$ as reported by ICE (2019).

\subsection{Cabling:}

Emissions for cabling were calculated based on Eq. 4:

$$
C_{\text {Cable }}=\left(k W * C E_{\text {Cable }}\right) / 44 * 12 \text { (Eq 4) }
$$

Where $\mathrm{C}_{\text {cable }}$ (tonnes carbon) is the total carbon flow associated with cabling production and $\mathrm{CE}_{\text {cable }}$ (tonnes $\mathrm{CO}_{2}$ ) representing the $\mathrm{CO}_{2}$ emissions resulting from production of cabling required for one $\mathrm{kW}$ of solar park. 
To maintain accuracy, the user needs to enter the cable weight and emissions associated with the actual cabling used. However, if the user does not have a site-specific value for cabling emissions, they can use the suggested values provided. For cabling, the estimate is based on figures by Mason et al. (2006) of $35 \mathrm{t} \mathrm{CO}_{2}$ eq./MW (0.035 t CO ${ }_{2}$ eq./kW).

\subsection{Inverters:}

Emissions for inverters were calculated using Eq. 5:

$$
C_{\text {Invert }}=\left(k W * C E_{\text {Invert }}\right) / 44 * 12(\mathrm{Eq} 5)
$$

Where $\mathrm{C}_{\text {Invert }}$ (tonnes carbon) is the total carbon flow associated with inverter production and $\mathrm{CE}_{\text {Invert }}$ (tonnes $\mathrm{CO}_{2}$ ) represents the $\mathrm{CO}_{2}$ emissions resulting from production of inverters required for one $\mathrm{kW}$ of solar park.

Industry reports indicate significant variation in emissions values for inverters, with SMA suggesting emissions of $0.17 \mathrm{~kg} \mathrm{CO}_{2}$ per kW inverters produced in 2018 for their German factories (SMA, 2018), but $0.68 \mathrm{~kg} \mathrm{CO} 2$ per $\mathrm{kW}$ inverters produced abroad (SMA, 2018). This is partially due to the variety of types of inverters available, including centralised and string, making it difficult to provide a robust suggested "average" value for users to apply to their park. Consequently, users are advised to provide actual emissions for their inverter requirements as per manufacturer information. If this is not possible, they should utilise the generic approach for technological carbon flows discussed earlier, which includes centralised inverters within emissions estimates based on well cited values of Mason et al. (2006).

\subsection{Switchgear/transformers:}

Calculated based on Eq. 6:

$$
C_{\text {Switch }}=\left(k W * C E_{\text {Switch }}\right) / 44 * 12(\mathrm{Eq} 6)
$$

$\mathrm{C}_{\text {switch }}$ (tonnes $\mathrm{C}$ ) is the total carbon emissions for switchgear/transformers, with $\mathrm{CE}_{\text {Switch }}$ (tonnes $\mathrm{CO}_{2}$ ) representing the $\mathrm{CO}_{2}$ emissions resulting from production of this equipment required per $\mathrm{kW}$ of solar park.

A suggested average value for the emissions of switchgear/inverters per $\mathrm{kW}$ was not found in the literature, likely due to the complexity associated with this type of equipment. Consequently, this value must be inputted by the user based on their site-specific setup. If the user does not have a suitable value for this, it is suggested that they make use of the generic 
approach to technological carbon flows, based on estimates by Mason et al. (2006) discussed earlier.

\subsection{Fencing:}

Fencing carbon costs were calculated based on Eq. 7:

$$
C_{\text {Fence }}=\left(k W * C E_{\text {Fence }}\right) / 44 * 12(\text { Eq 7) }
$$

$\mathrm{C}_{\text {Fence }}$ (tonnes carbon) is the total carbon emissions for fencing production, with $\mathrm{CE}_{\text {Fence }}$ (tonnes $\mathrm{CO}_{2}$ ) representing the $\mathrm{CO}_{2}$ emissions resulting from production of fencing required for one $\mathrm{kW}$ of solar park.

The user is able to enter the actual emissions related to their site-specific requirements for fencing into the SPCC. However, as fencing requirements are generally fairly similar between solar parks (around the perimeter of the site), a suggested estimate for fencing emissions is also provided within the SPCC, based upon the database of 1,032 digitised UK solar parks. The average perimeter per MW was calculated for all of the solar parks in the database, and as it is assumed that fencing goes along the perimeter, the length this produced was assumed to be the length of fencing required per MW of solar installation in the UK. This resulted in an average of $348 \mathrm{~m}$ of fencing required per MW (0.348 per kW) of solar park installed. The estimated requirement of steel for $348 \mathrm{~m}$ of $2.0 \mathrm{~m}$ High ' $V$ ' Mesh Security Fencing (similar to fencing recommended as best practice in (NSC, 2013) was found to be 2,390 $\mathrm{kg}$ from the weight of fencing components that would cover this distance (116 times 3-m sections at $20.6 \mathrm{~kg}$ each - acquired from First Fence (ND). This weight of steel was then multiplied by the standard emissions for producing one $\mathrm{kg}$ of steel (ICE, 2019) to provide a suggested value of 3.7 tonnes $\mathrm{CO}_{2}$ emissions per $\mathrm{MW}\left(0.0037\right.$ tonnes $\mathrm{CO}_{2}$ per $\mathrm{kW}$ ) of solar park.

\subsection{Other Raw Materials:}

Whilst the above detailed components are those consistently required, stakeholder discussions highlighted the occasional use of additional materials (e.g., concrete, glass, copper). Consequently, there is space within the tool to add additional materials that may be required by the user. The emissions based on these materials are added to provide a total emissions number (Eq. 8):

$$
C_{\text {other }}=\sum\left(Q_{a, b, c \ldots} * C E_{a, b, c . . .}\right) / 44 * 12 \text { (Eq 8) }
$$

Where $\mathrm{C}_{\text {Other }}$ (tonnes carbon) is the total carbon flow associated with additional material production, $\mathrm{Q}(\mathrm{kg})$ represents the quantity of the material required as specified by the user 
and $\mathrm{CE}$ (tonnes $\mathrm{CO}_{2}$ per $\mathrm{kg}$ material produced) is the associated carbon emissions factor of said material.

It is important to note that this section is primarily focussed on raw materials associated with construction, with other resources (e.g., data connectivity) included in the additional resource section below.

\subsubsection{Transportation of components}

To estimate the emissions due to transportation of components, users are required to input the transportation method, weight of cargo and distance (Eq. 9). The likely emissions values for common transportation methods were based on those provided by Time for Change (ND).

$$
C_{\text {Transport }}=\sum\left(D_{a, b, c \ldots} * T R_{a, b, c \ldots}\right) / 44 * 12 \text { (Eq 9) }
$$

$\mathrm{C}_{\text {Transport }}$ (tonnes carbon) is the total carbon emissions from transportation, calculated as the sum of D - transport distances $(\mathrm{km})$ multiplied by TR - transport emission factor (tonnes $\mathrm{CO}_{2} /$ tonne $\mathrm{km}$ ) for each specific component. This is based upon the distance in $\mathrm{Km}$ and the specific emissions factor associated with the transport method chosen by the user.

Two further features were added in order to allow estimation of transportation emissions when these are not known by the user. These were included primarily for the panels due to their significance to the overall carbon costs of a solar park, but they can also be applied to other components whenever relevant. Firstly, following the suggestion of Frischknecht et al. (2020) that the majority of panels are produced in China or the EU, two case study shipping routes were added based on this.

- In the Chinese case study, shipping for panels was determined to be 13,644 sea miles in distance from Ningbo port in China to Felixstowe, UK. Ningbo port was closest to Jinko Solar's two main factories of Shangrao and Haining where $85 \%$ of panels are produced (JinkoSolar, 2018), whilst Felixstowe is the main port in the UK for deliveries from China.

- Shipping from Germany was estimated as $800 \mathrm{~km}$ via truck, as Germany is the largest manufacturer of solar equipment within Europe (Jäger-Waldau, 2006).

The other feature is an estimate of panel weight for shipping in case this is not known by the user. The number of panels is estimated from the desired output and average output per panel. The average weight per panel was then applied to get the likely shipping weight for the 
development. Although future versions may be able to include these estimates for other components, this information was not available for the current SPCC and so the focus remained on the panels due to their overall significance to a solar park (Todde et al., 2018).

\subsubsection{Machinery Use}

Discussions with developers highlighted that machinery use largely consists of piledrivers for mounts, excavators for underground cabling and lifting equipment to position panels, with requirements for each dependent on the specific location and practices. Consequently, actual site-specific information provided by the user is key for this element to calculate total emissions (Eq. 10):

$$
C_{\text {Machine }}=\sum\left(C E_{a, b, c \ldots} * t_{a, b, c \ldots}\right) / 44 * 12 \text { (Eq 10) }
$$

$\mathrm{C}_{\text {Machine }}$ (tonnes $\mathrm{C}$ ) is the total carbon emissions of machinery use. $\mathrm{CE}_{\mathrm{a}, \mathrm{b}, \mathrm{c}}$ (tonnes $\mathrm{CO}_{2} /$ hour) refers to the emissions factor for certain machinery, multiplied by $t_{a, b, c . . .}$ (hours) referring to the time the user estimates the equipment will be used for.

Users should provide the average emissions per hour of their specific equipment used as per manufacturer guidance, alongside the specific time they require each of these pieces of equipment. Where this is not available, it is advised the user adopts the generic approach, as this includes machinery emissions as per Mason et al. (2006).

\subsubsection{Additional resource use}

There are a number of additional resource requirements, including data connectivity that can vary according to the solar park design. Although these could contribute significantly to carbon flows, variation between solar parks means that these have been left for the Discussion.

\subsubsection{Construction - Ecosystem}

\subsubsection{Soil carbon}

Soil carbon stocks are influenced by a number of processes during the lifetime of a solar park, primarily due to changes in land use and management (Ostle et al., 2009). Soil carbon changes will occur in areas where the land surface is completely covered, such as underneath buildings or access roads. Due to uncertainty as to the carbon cycling processes under panels (Armstrong et al., 2016) and lack of any field data, areas under panels were assumed to retain 
the same soil carbon stocks as the land use before the solar park was constructed. Changes in soil carbon are quantified for land use change to a solar park by deducting the original carbon stocks from those within the new land use, with both figures acquired by multiplying the land area by soil carbon stocks determined by the soil carbon review mentioned earlier. The user is able to select the previous land use from a list of options which correspond to the 21 land use categories of the Morton et al. (2020) UKCEH 2019 Land cover map (LCM), before inputting the size of the land area they intend to develop on, and the SPCC will then provide an estimate of soil carbon for the area in question. The calculations assume that the new land cover is either grassland, urban or the same as previously defined. Although these impacts on soil carbon are quantified within the construction section of the SPCC, as they begin with solar park construction, it should be noted that these impacts continue on through the operation phase of the solar park. Consequently, they would ideally be incorporated dynamically (further information on this can be found in the Discussion).

Changes in soil carbon stocks are calculated based on the impact of complete coverage, shading and open areas. These are discussed in more detail below.

\subsection{Complete land surface coverage}

Changes to soil carbon due to complete coverage of the land surface with access tracks or buildings are calculated in the SPCC as the soil carbon of the area under "urban" land use (Morton et al., 2020), minus the soil carbon of the original land use defined by the user (Eq. 11). Areas of complete coverage should include any land which is covered by access tracks and buildings (i.e., associated with transformers, inverters, energy storage units, DNO substations and customer substations). The construction compound could also be included within this, but that is discussed in more detail in the discussion section.

$$
\Delta \boldsymbol{C S}_{\text {Complete }}=\left(\boldsymbol{A}_{\text {Complete }} * \boldsymbol{S} \boldsymbol{R}_{\text {Urban }}\right)-\left(\boldsymbol{A}_{\text {Complete }} * \boldsymbol{S} \boldsymbol{R}_{\text {Original }}\right)(\text { Eq 11) }
$$

Where $\Delta \mathrm{CS}_{\text {complete }}$ (tonnes carbon) is the change in soil carbon due to complete coverage, $\mathrm{A}_{\text {complete }}(\mathrm{ha})$ is the area of complete coverage, $\mathrm{SR}_{\mathrm{urban}}$ (tonnes carbon/ha) is the average soil carbon rate for urban land use, and $\mathrm{SR}_{\text {original }}$ (tonnes carbon/Ha) is the average soil carbon rate for the original land use, defined by the user.

If users do not have their own values for this coverage, they are able to use suggested average values. Average coverage for access tracks was found to be $2.3 \%$ according to the digitised 
solar park database, whilst other building coverage was $0.3 \%$, providing combined complete coverage of $2.6 \%$ of total land coverage (see Methods for details).

\subsection{Shading}

Due to uncertainty as to the carbon cycling processes under panels (Armstrong et al., 2016), areas under panels were assumed to retain the same soil carbon stocks as the land use before the park was constructed, calculated as the area of solar panel coverage multiplied by the soil carbon rate of the previous land use as defined by the user. Although this is not quantified as a change to soil carbon, this is vitally important in order to estimate the overall carbon costs of land use change, as well as to highlight a gap for the insertion of novel information.

If the user does not have the solar panel area coverage available, they are able to use a suggested value of $0.8 \mathrm{ha} / \mathrm{MW}$ installed capacity $(0.0008 \mathrm{ha} / \mathrm{kW})$, which was derived from the average solar panel area coverage of 1,032 digitised UK solar parks (unpublished data).

\subsection{Open areas}

Due to uncertainty regarding soil carbon flows within a solar park (Armstrong et al., 2016), all other changes to soil carbon were calculated based on changes resulting from the previous user-defined land use to grassland, as this is how most UK sites are managed for the lifetime of the solar park (Armstrong et al., 2016) (Eq 12):

$$
\Delta C S_{\text {open }}=\left(A_{\text {open }} * S R_{\text {Grassland }}\right)-\left(A_{\text {open }} * S R_{\text {Original }}\right)(\text { Eq 12) }
$$

Where $\Delta \mathrm{CS}_{\text {open }}$ (tonnes carbon) is the change in soil carbon due to land use change of open areas, $\mathrm{Aopen}_{\mathrm{O}}(\mathrm{Ha})$ is the area of open land, $\mathrm{SR}_{\text {Grassland }}$ (tonnes carbon/ha) is the soil carbon rate of grassland areas.

Area of open areas can be determined by deducting the areas of complete coverage and shading from the total solar park coverage (Eq 13):

$$
A_{\text {Open }}=A_{\text {Total }}-A_{\text {Shade }}-A_{\text {Complete }} \text { (Eq 13) }
$$

Although it is likely that most users will have site specifics available, which should include the total solar park area, this may not always be the case. Thus, suggested figures are included for users as a guide when specifics are not available. This is based on an average land area of 1.96 ha per MW (see Methods). This value was compared to similar values in Solar Energy UK's 
natural capital report (Solar Trade Association, 2019) that solar parks in the UK currently use between 1.6 and 2 ha per $1 \mathrm{MW}$ capacity $(0.0016-0.002$ per kW).

\subsubsection{Aboveground Biomass}

Aboveground biomass carbon is quantified in a process identical to that described above for soil carbon stocks. Again, it is important to note that although these impacts on aboveground biomass carbon are quantified within the construction section of the SPCC, as they begin with solar park construction, it may take a couple of years for vegetation to fully develop if the site is seeded. Further information on this can be found in the Discussion.

Values for carbon content of aboveground biomass per ha were acquired from Milne and Brown (1997) for a number of land use types. Although information was not present for all of the 21 land use types included in the UKCEH LCM, it was deemed that those available in this study were sufficient, since discussions with developers highlighted that solar parks would typically not be present on heavily wooded areas.

Change in aboveground biomass carbon is calculated based on the impact of complete area coverage with solar panels, shading and open areas. These are discussed in more detail below.

\subsection{Complete coverage}

Complete coverage is also relevant to aboveground biomass as this not only requires the complete clearance of any aboveground biomass that would have been present in these areas, but this also prevents the growth of aboveground biomass for the duration of the solar park's lifetime. As it is assumed that no aboveground biomass will grow in areas of complete coverage, this loss can be calculated simply as Eq 14:

$$
\Delta \boldsymbol{C A}_{\text {Complete }}=0-\left(\boldsymbol{A}_{\text {Complete }} * \boldsymbol{A R}_{\text {Original }}\right)(\text { Eq 14) }
$$

Where $\Delta C A_{\text {complete }}$ (tonnes carbon) is the change in aboveground biomass carbon due to complete coverage, equal to $0, A_{\text {complete }}(\mathrm{ha})$ is the area of complete coverage and ARoriginal (tonnes carbon/ha) is the aboveground biomass rate of the area as grassland (how it is managed during solar park lifetime). 


\subsection{Shading}

Based on the findings of Armstrong et al. (2016), aboveground biomass under solar panel areas are estimated to be $25 \%$ of the rate typical for open grassland areas (Eq 15). The user is asked to input the solar panel coverage area of their site in order to calculate this.

$$
\left.\Delta \boldsymbol{C} \boldsymbol{A}_{\text {Shade }}=\left(\boldsymbol{A}_{\text {Shade }} * \boldsymbol{A} \boldsymbol{R}_{\text {Grassland }}\right) * 0.25\right)-\left(\boldsymbol{A}_{\text {Shade }} * \boldsymbol{A} \boldsymbol{R}_{\text {Original }}\right)(\text { Eq 15) }
$$

Where $\Delta C A_{\text {shade }}$ (tonnes carbon) is the change in aboveground biomass carbon due to shading, being equal to the area of shading $A_{\text {shade }}$ (ha) multiplied by $A R_{G r a s s l a n d}$ (tonnes carbon/ha), which is the aboveground biomass rate of that area (multiplied by 0.25 ), less the same area $A_{\text {shade }}$ (ha) times ARoriginal (tonnes carbon/ha), which is the original aboveground biomass carbon of that area.

The user is able to input the same suggested values for solar panel coverage as highlighted earlier for soil carbon if they do not have their own values (section 3.3.4.1.2).

\subsection{Open Areas}

As with soil carbon, any areas which are not impacted by complete land coverage for solar panels or shading fall into the open area category and are analysed justly. For these areas, aboveground biomass carbon is calculated based upon the area being managed as a grassland, similarly for the soil carbon considerations (Eq 16).

$$
\Delta C A_{\text {Open }}=\left(A_{\text {open }} * A R_{\text {Grassland }}\right)-\left(A_{\text {Open }} * A R_{\text {Original }}\right)(\text { Eq 16) }
$$

Where $\Delta C A_{\text {open }}$ (tonnes carbon) is the change in aboveground biomass carbon due to land use

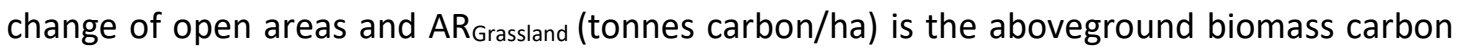
rate of grassland areas.

\subsubsection{Construction practices}

The impact of construction practices such as ground compaction and trenching for underground cabling should also be considered as these have the potential to impact both soil carbon and aboveground biomass carbon. However, these are addressed in the Discussion section due to uncertainty in their quantification. Also, it was not possible to quantify the impact of the construction compound on ecosystem carbon flows during the construction phase of the solar park. 


\subsubsection{Operational - Technological}

\subsubsection{Offsetting potential}

To determine the potential carbon offset of the solar park through low carbon electricity generation, the electricity output of the park must be quantified. This allows for an estimate of carbon emissions that would occur if the same quantity of electricity were to be produced by the grid mix.

Solar Park Output: The solar park output is estimated using Eq. 17:

$$
E_{\text {output }}=8760 * \boldsymbol{k W} * \mathrm{CF}(\mathrm{Eq} 17)
$$

Eoutput $(\mathrm{kWh})$ is the yearly electricity output, equal to hours in year (8760), multiplied by nameplate capacity in kW, multiplied by CF (No units) referring to Capacity Factor. The capacity factor was estimated based on the output of all UK solar parks (GOV UK, 2020).

Avoided grid emissions: The yearly electricity generated (kWh) is multiplied by the average carbon intensity of the grid per kWh to determine the carbon offset in one year of electricity generation (Eq 18):

$$
C_{\text {Offset }}=\left(E_{\text {Output }} * G I\right) / 44 * 12(\text { Eq 18) }
$$

$\mathrm{C}_{\text {offset }}$ (tonnes carbon) is equal to the electrical output * $\mathrm{Gl}$ (tonnes $\mathrm{CO}_{2} / \mathrm{kWh}$ ) as the current Grid Intensity as determined by the user.

Up to date information about the grid carbon intensity of a country/region can be located online through a quick web search, but in case the user cannot gain access to this information, there are a number of reference values within the tool, including the UK electricity emissions factors up to 2100 from (DECC, 2019).

\subsubsection{Missing components}

Due to limited information available, a number of components were not quantified within this subsection. These include the manufacture of replacement components, backup generation, machinery and resource use for solar park maintenance and the energy (electricity) used in the duration of the solar park for components such as tracking systems, lighting, heating, and cooling and any other requirements during solar park operation. 


\subsubsection{Operational - Ecosystem}

\subsubsection{Soil Carbon}

There are a number of processes during the operational phase of a solar park that will likely affect soil carbon. Those already quantified within construction include complete coverage and open areas (see section 3.3.4.1). Impacts following from construction practices, as well as continued management practices that may cause soil erosion and ground compaction, will also be relevant here. Microclimate impacts, including the impacts of shading, although currently not quantified (Armstrong et al., 2016), should also be considered. No further quantification of these is included in this version of the SPCC, so more information about these potential impacts to soil carbon can be found in the Discussion.

\subsubsection{Aboveground Biomass}

Although most of these have already been highlighted in the construction section, there are a number of processes during the operational phase of a solar park that will likely affect aboveground biomass carbon. Those already quantified within construction include complete coverage, shading and open areas (see section 3.3.4.2). Impacts due to management practices that lead to the clearing of vegetation will also be relevant here, however no further quantification of these is included in this version of the SPCC, with more information about these potential impacts to aboveground biomass carbon found in the Discussion.

\subsubsection{Management Interventions}

Although these are not quantified within the current SPCC, there are a number of solar park management practices that could influence both soil and aboveground biomass carbon stocks and flows. These include practices to enhance biodiversity, like mowing, grazing, seeding and nutrient addition. The extent to which these practices are employed will determine if a site experiences positive or negative carbon flows (Randle-Boggis et al., 2020).

\subsubsection{Decommissioning}

Decommissioning impacts of technological and ecosystem components were not included given the relative novelty of UK ground mounted solar parks, meaning there is very little available information about the end-of-life treatment of these installations. As more solar 
parks meet maturity and new legislation is created to govern these practices, quantification may become possible, but for now these components are not included in the SPCC.

\subsubsection{Technological}

Technological components that are not quantified consist of: machinery emissions to remove any components, transportation to waste site, emissions and energy use during recycling and any negative emissions to be attributed to the recycling of materials (offset production of new materials).

\subsubsection{Ecosystem}

Ecosystem components that are not quantified include costs to soil and aboveground biomass carbon due to any land use changes at the end of a solar park lifetime, any further damage from machinery in deconstructing the solar park (including ground compaction and soil erosion), removal of cables and any on-going site management, including subsequent rewilding.

\subsubsection{Carbon Payback Time}

Assuming the user has inputted all of the previous information in the tool, the carbon payback time can be calculated with a simple equation Eq. 19:

$$
C P B T=\frac{C_{\text {Total }}}{C_{\text {offset }}}(\text { Eq 19) }
$$

Where CPBT refers to the carbon payback time (years), $\mathrm{C}_{\text {Total }}$ (tonnes carbon) is the total carbon release of construction, operation, and decommissioning, and $\mathrm{C}_{\text {offset }}$ refers to the annual carbon savings from electricity generation defined in Eq. 20.

Although the denominator is defined in section 3.3.5.1, $\mathrm{C}_{\text {Total }}$ is a summation of all other carbon flows defined in the calculator through construction, operation, and decommissioning phases. This is computed below (Eq. 20):

$$
C_{\text {Total }}=C_{\text {Tech }}+C_{E c o}(\text { Eq 20) }
$$

Where $\mathrm{C}_{\text {Tech }}$ (tonnes carbon) is the summation of all technological carbon costs quantified in the calculator and $\mathrm{C}_{\mathrm{Eco}}$ (tonnes carbon) is the summation of all ecological carbon costs quantified in the calculator (this could be positive or negative). 
Total technological carbon costs are defined as the summation of all carbon costs defined within the technological sections of the SPCC (Eq. 21):

$$
C_{\text {Tech }}=C_{\text {Man }}+C_{\text {Transport }}+C_{\text {Machine }}(\text { Eq 21) }
$$

Total ecosystem carbon is defined as the summation of all changes to soil and aboveground biomass carbon calculated within the SPCC (Eq 22). It is important to note that this may be positive or negative:

$$
C_{E c o}=\Delta C S_{\text {Complete }}+\Delta C S_{\text {open }}+\Delta C A_{\text {Complete }}+\Delta C A_{\text {Shade }}+\Delta C A_{\text {Open }} \text { (Eq 22) }
$$

\subsection{Discussion}

\subsubsection{Construction - Technological}

\subsubsection{Manufacture of components}

\subsection{Panels}

Existing literature highlights that the panels are likely to represent the single largest carbon cost within a solar park, both within the technological aspects and potentially for the solar park as a whole. This is largely due to energy intensive processes associated with resource extraction and manufacture, with up to $80 \%$ of overall energy required to produce the panel modules (Todde et al., 2018). Consequently, it is critical that their carbon impacts are as accurate as possible to ensure robust estimates from the SPCC. Although there is the option to use a generic value within the SPCC, actual panel data, including country of manufacture, can have a significant effect on the associated carbon emissions.

A range of panel types were included within the SPCC due to the availability of information from de Wild-Scholten (2013). However, silicon based panels are the most common, as they comprised up to 95\% of panels produced in 2019 (Fraunhofer Institute for Solar Energy Systems, 2020). The importance of CdTe panels was also highlighted by Nelson et al. (2014), with up to $12 \%$ of UK market share, being the largest other single contributor to overall market share. Care should be taken when making comparisons between these two technologies, as Nelson et al. (2014) demonstrated how CdTe panels produce $600 \mathrm{~kg} \mathrm{CO} / \mathrm{kW}$, compared to $1,500-2,500 \mathrm{~kg} \mathrm{CO}_{2} / \mathrm{kW}$ for C-Si panels. However, it was also recognised that other more toxic waste is left behind by CdTe panels, which is not the case with silicon panels. Future versions of the SPCC may include the quantification of toxic outputs of solar waste, but for now it should 
be in the interest of developers to be aware that a lower carbon cost in this area may not necessarily mean lower environmental impacts overall.

Panel origin has a significant impact on carbon flows as carbon intensity by output increases from around 20 to $40 \mathrm{~g} \mathrm{CO}_{2} / \mathrm{kWh}$ for manufacture and deployment in Europe, to $80 \mathrm{~g} \mathrm{CO}_{2} / \mathrm{kWh}$ for manufacture in a coal dominated economy such as China (Nelson et al., 2014). This could have significant impacts on the SPCC estimates, especially as Frischknecht et al. (2020) found that $72 \%$ of the panels installed in Europe in 2018 were produced in China, while the remaining $28 \%$ were produced in Europe. Therefore, inclusion of solar panel manufacturing location is critical for accurate SPCC estimates.

The use of bi-facial panels was explored as a future technology for UK solar parks. Consultation with solar park developers signified that these were likely to become more prominent in future years as manufacturing costs decrease. Early controlled experiments demonstrated that bifacial panels could increase electricity generated by up to 59\% (Luque et al., 1985), signifying that these could be a significant component to consider in the future as their prominence increases. However, there has been limited literature on the field application of these technologies, resulting in the omission within this version of the SPCC. Future versions could include quantification of the benefits of bifacial panels as a \% benefit to overall electricity generated. If this is to be the case, any changes in emissions due to the panel production should also be assessed.

\subsection{Mounts}

Although historically panels have been the most energy, and therefore carbon, intensive components, recent technological improvements have meant that BOS components are now becoming far more significant (Szilágyi and Gróf, 2020). This is particularly relevant to mounting structures, with high quantities of raw materials equating to significant carbon costs. For example, Szilágyi and Gróf (2020) found mounts comprised 30\% of the total carbon impact in their study due to steel production. This signifies that efforts should be made to ensure these carbon contributions are accurately resolved in the SPCC.

Beylot et al. (2014) highlighted that significant gains, and thus carbon savings, in electricity generation could be made due to tracking systems, with single axis systems increasing generation by $5 \%$ and dual axis trackers bringing $32.5 \%$ increase in electricity. Thus, tracking systems were included in the SPCC. However, the carbon savings will vary greatly dependent on actual site information. Moreover, the difference in the carbon cost of tracking mounts - 
not only due to different material demands, but due to the complexity of these components which have many moving parts and thus may require more maintenance - needs to be resolved.

Future versions of the SPCC may consider different materials for mounting structures, as well as the benefits of tracking. In addition to tracking or stationary mounts, Beylot et al. (2014) highlighted alternative materials to steel are also available for panel mounts. Aluminium mounts had a higher carbon cost, but there is potential for savings if these are made from recycled materials. Wooden mounts had a much lower carbon cost, but the increased rate of decay means these are unlikely to be utilised as best practice.

The use of concrete platforms to support mounting structures was highlighted as a potential consideration as some solar parks employ these as foundations. The increased material intensity of this method could bring significant carbon impacts through the production and transportation of large volumes of concrete. However, discussions with industry professionals highlighted that this was not common practice in the UK and thus would be of minimal significance to the SPCC.

\subsection{Cabling}

All solar parks require cabling, with potential for significant emissions due to copper requirements. Consequently, inclusion of cabling in the SPCC is important but the overall impact will depend on site setup. Consequently, user input is important to obtain accurate results for cabling. Within the SPCC, Mason et al. (2006) estimates are used as a guideline if users do not have the figures for their site, as it is a well cited study based on a ground mounted PV system.

\subsection{Inverters}

Literature and discussions with developers both highlighted that developers may choose to employ string inverters on every row of panels or central inverters that connect larger areas of the site, with each option having its own disadvantages and benefits. However, string inverters are becoming increasingly common in the UK, due to cost savings and ease of maintenance once installed (given ability to change individual strings without impacting large areas of the solar park). Consequently, the carbon flows associated with production of these components should be refined and included in the SPCC. The current version of the SPCC does not distinguish between string and centralised inverters when the user has their own 
information available, as this input is based on emissions per $\mathrm{kW}$ rather than per inverter. However, the generic approach for technological emissions only includes information based upon centralised inverters, as these are used within Mason et al. (2006). Limited other data are available. Future versions of the SPCC may include a comparison between string and centralised inverters if this information becomes available, as it may contextualise the decisions that developers will be making in terms of inverter setup.

As for panels, variation in reported emissions from different manufacturing locations of invertors has been found. For example, for one of the largest inverter manufacturer's emissions varied threefold; $0.17 \mathrm{~kg} \mathrm{CO} / \mathrm{kW}$ for inverters produced for SMA in Germany and $0.62 \mathrm{~kg} / \mathrm{kW}$ for inverters produced outside of Germany (SMA, 2018). Consequently, including location of origin is critical for the SPCC.

\subsection{Switchgear, transformers, and battery storage}

Discussion with industry experts highlighted that it is common practice to only build a solar park where a grid connection is available; it is unlikely solar parks will be economically feasible otherwise. This means that, although the emissions for switchgear are included, this only refers to smaller electrical substations and not new grid connection infrastructure. In addition to this, onsite storage of the energy produced by solar parks should be considered in future versions of the SPCC as it is becoming increasingly common practice.

\subsection{Fencing}

Fencing was deemed an important component of a solar park due to the recommendation of the BRE guidelines to utilise close welded mesh panel fencing as good practice to avoid criminal damage within solar parks (NSC, 2013). Since this fencing is typically $2 \mathrm{~m}$ in height and mostly consists of galvanised steel posts connected by mesh fencing, there is the potential for significant emissions from raw material production, indicating its inclusion within the SPCC is important.

\subsection{Other Raw Materials}

Due to uncertainty around the emissions related to the actual components of a solar park, it is possible for the user to include emissions factors for a number of additional raw materials. Discussions with industry professionals highlighted several raw materials that may be important to construction, including concrete, glass, PVC, GRB, aluminium, copper, and steel, 
for various reasons (e.g., construction of an auxiliary building). Access roads were particularly relevant here as specific information on materials for producing these was not present, so a value for emissions of gravel was included to allow the user to input based on this.

\subsubsection{Transportation of components}

The importance of transport emissions in the overall carbon payback time of a renewable source was highlighted in 15 of the 27 papers included in the literature review (Chapter 2), including three of the four studies on solar PV. It was necessary to calculate this within the SPCC as the method of transportation to a site is likely to depend on the distance, and different transportation methods can have significantly different emissions. This was particularly important for the construction section as the bulk of moving components to site would be completed at this stage. Consequently, emissions factors for a number of different transportation methods were provided to allow the user to calculate emissions based on actual cargo. Although some transportation emissions would be present from "other raw materials", these were not included within the SPCC due to the likelihood that these would constitute minimal quantities and the fact these would be sourced from multiple locations.

\subsubsection{Machinery emissions}

Several studies included in the literature review highlighted the potential carbon emissions from machinery use throughout the lifetime of a solar park. This was particularly common in bioenergy studies, where agricultural equipment was required to produce the energy crop (Souza et al., 2012). More specific to solar PV, studies such as Desideri et al. (2012) considered the emissions of the specific equipment used to construct the facilities. Although the actual dimensions and duration of use of the machinery required will vary dependent on the location in question, discussions with professionals and the literature review have highlighted that machinery use during the construction of a UK solar park is likely to be fairly minimal. This is with the exception of transportation equipment which is calculated separately (see section 3.4.1.2). Due to these minimal requirements, it is unlikely that new machinery will be made for the construction of a solar park. Since this equipment will likely be rented, only the emissions due to their use should be included in the SPCC. The user should be able to provide the actual emissions values for their equipment use, but if this is not possible, they are advised to make use of the generic approach, as this includes information on construction based on (Mason et al., 2006). 


\subsubsection{Additional resource use during construction}

Other than the additional raw materials already discussed, there are a number of additional resources that may be required in the construction of a solar park. This could include water usage, connectivity and data supply. As these factors may vary significantly depending on the site location and solar park setup, they need to be considered on a case-by-case basis and quantified wherever possible in future versions of the SPCC.

\subsubsection{Construction - Ecosystem}

\subsubsection{Soil Carbon}

Due to large quantities of carbon stored within soils (Lal, 2004), and that increasing soil carbon is a policy focus (DEFRA, 2020), it was important to include this within the SPCC. Due to the sparse literature currently available regarding the impacts of solar parks on soil carbon, a land use change approach was adopted, allowing for a simple two-timestep model demonstrating stocks of carbon before and after land use change based on soil carbon review data (see Methods). Some studies like Dawson and Smith (2007), Ostle et al. (2009) and Milne and Brown (1997) included figures that could potentially be utilised to quantify carbon accumulation during the period of land use change, however the uncertainty of application to solar parks negated inclusion. Also, the increase in complexity of modelling would have provided a much higher uncertainty with estimates, ensuring that this was left out of this version, but could be included in future versions of the SPCC.

Although the quantification of soil carbon impacts within the SPCC has appeared within the construction phase given these impacts begin during construction, it is important to highlight how these impacts will continue throughout the operation phase of the solar park, with soil carbon stocks often taking many years to reach new equilibrium (Smith, 2014). The use of a two timestep model allows the estimate of what soil carbon will look like under the new land use, but does not completely capture the dynamic processes occurring. However, for completeness, the impacts previously highlighted in the results will still be discussed within this construction phase.

Given the differences in land coverage within a solar park, impacts on soil carbon were derived for three separate zones: complete coverage, shading and open areas. 


\subsection{Complete Coverage}

Although the solar park itself may typically cover a large area of land, some of which is over sailed by solar panels, only a small land area is completely covered, e.g., access tracks. However, the impacts of complete coverage of the land on soil carbon will potentially have a large impact from processes such as drainage and compaction. Despite the relatively minimal complete coverage of solar parks compared to total or panel coverage, the higher potential impacts brought about by complete coverage, justifies its inclusion within the SPCC. Although they used "urban" land cover type, Morton et al. (2020) estimates were deemed suitable for quantification of soil carbon within the current SPCC, due to likely similarities in building/track coverage to those of urban infrastructures. Future versions of the SPCC should quantify these impacts based on soil carbon data acquired from areas of complete coverage at UK solar parks.

\subsection{Access tracks}

After the construction of a solar park, there will likely be much lower requirements for heavy machinery to access the solar park. However, vehicle access will likely still be necessary for maintenance and cleaning purposes. As a result, access tracks are an important feature within solar parks and thus included in the SPCC. Depending on the size and location of the solar park, there will be different requirements for access roads or tracks within the site. Beylot et al. (2014) suggested that $5 \%$ of the total area of a solar park could consist of tracks. However, measurements based on digitised UK solar parks found access tracks to be around $2.3 \%$, which was considered a more suitable figure due to being based on UK sites. Beylot et al. (2014) also suggested that there would be $3 \mathrm{kms}$ of roads needed for site access. Discussions with industry professionals highlighted that within the UK, it would be extremely rare to install new roads for a solar park development, so this was not included in the SPCC. Future versions of the SPCC may quantify the benefits of utilising different styles of access tracks, as discussions with developers highlighted how plastic matting has increased in popularity over recent years. This style of matting allows grass to grow between the gaps and could be seen as a management technique that could increase carbon sequestration of a solar park area through improvements to soil carbon storage.

\subsection{Buildings}

Different decisions made by developers, such as whether to include centralised or string inverters, has an impact on the amount of building coverage within a solar park, and as a result it was important to bring awareness to the impact these buildings may have on the carbon 
flows within a solar park. Future versions of the SPCC may quantify each type of building separately in order to encourage developers to analyse which buildings are essential, and which could be minimised in order to reduce overall impact on the hosting ecosystem.

\subsection{Construction compound}

Discussions with industry professionals highlighted that during the construction phase of a solar park, there would be the requirement to set up a construction compound to hold equipment for the site. This would be the area where all deliveries and heavy construction equipment are stored and where temporary facilities for workers are built. There is thus potential for significant impacts associated with clearance of biomass and loss and/or compaction of soils. The temporary nature of this compound, combined with the contractual obligation for contractors to return land to suitable condition before construction is complete, have meant that this is not quantified within the SPCC. However, this may be a consideration for future versions.

\subsection{Shading}

As solar panels are the main component within a solar park, it is vital to consider their potential impact on the hosting ecosystem. Although there is currently no evidence regarding changes to soil carbon due to panel coverage (Armstrong et al., 2016), the fact that aboveground biomass is one of the greatest inputs to soil carbon stocks (Milne and Brown, 1997), suggests that future SPCCs should quantify any impacts this process may have on soil carbon storage, as this may be significant. The current assumption applied to the SPCC is that soil carbon remains equal to the land use present before the solar park, with a carbon change of zero in these areas. This may not completely capture the dynamic nature of soil carbon stocks (Smith, 2014). However, this is much preferred to the alternative of estimating changes without credible data. Therefore, this current approach is suitable for the SPCC, and future versions should attempt to better quantify this aspect.

\subsection{Open Areas}

As discussions with industry experts highlighted solar parks are commonly managed as grasslands within the UK, it was deemed best practice to include this as the default option. Solar PV has a relatively low energy density compared to traditional fossil fuel electricity generation methods (Gagnon et al., 2002), so there is potential for significant amounts of land 
to experience this land use change. Considering large areas of land within a solar park will not experience panel shading or complete coverage, it is essential to include grassland soil carbon data within the SPCC. It is important to be mindful of the fact that, dependent on previous land use, this could result in carbon gain as well as carbon loss. For example, conversion from arable and horticultural land to improved grassland could lead to an increase of $\sim 6$ tonnes soil carbon per hectare (soil carbon review data).

\subsection{Construction Impacts}

The relatively short nature of construction activities compared to the longer recovery time the solar park area has during its operation made it difficult to quantify the possible impacts these construction activities may have on natural carbon flows, particularly within the context of a two timestep model. Furthermore, discussions with industry experts demonstrated that those undertaking the works are typically contractually obligated to restore the land by the time the solar park is operational, meaning a conscious effort is made to minimise disturbance. As Dawson and Smith (2007) suggests generally, disturbance to soil will be bad for soil carbon. Whenever this is reduced, it is assumed to be beneficial for soil carbon. Therefore, it is assumed that as long as best practice is followed, the impact from construction activities will be fairly minimal. However, these should be considered carefully before construction takes place, while future versions of the SPCC would benefit from the inclusion of these impacts.

\subsection{Erosion}

Assuming that the solar park is well managed as a grassland, erosion will primarily take place during construction. Although wind erosion is perhaps less likely for UK solar parks than for countries where grading of soils is common practice (Guerin, 2017), there is potential for erosion during times soils are left exposed. High levels of aeolian soil erosion of a solar park area could lead to reduced efficiency of solar panels through dust (Hernandez et al., 2014) as well as carbon losses through soil loss, meaning this should be a consideration made in future versions of the SPCC. Guerin (2017) mentions that the incidence soil erosion may be reduced by the presence of a buffer strip of vegetation and trees surrounding the solar park, allowing any dust to accumulate in these areas. Erosion of soils via water may also be an important consideration in the UK, where flooding is a common issue (Boardman, 2013). Poorly vegetated soils are more likely to experience erosion of the top layer of soil, especially in the areas at the edges of panels, where rainfall is concentrated from the panel face (Armstrong et al., 2016). Due to the inability to discern where the resulting carbon is deposited, any soil 
removed as a result of this process can be seen as a complete loss of any associated soil carbon in this layer. This may be particularly important as the topsoil of grassland environments constitutes approximately $32.4 \%$ of the total carbon stored in UK top-soils (Ostle et al., 2009). Completing construction works in summer months rather than winter months should reduce the incidence of soil erosion via water due to reduced rainfall.

\subsection{Compaction}

Hernandez et al. (2014) highlighted soil compaction as an issue pertinent to solar parks due to destruction of vegetation caused by construction equipment. Moreover, the UK Government highlighted within the State of the Environment Report (Environment Agency, 2019) that compaction of soils in England and Wales costs $£ 472$ million per year. Soil compaction has been proven to decrease the $\mathrm{CO}_{2}$ emissions of soil (Novara et al., 2012), resulting in a need to discuss this as a potential consideration for future SPCC versions. The Environment Agency (2019) also suggested that soil compaction is more likely to occur in times of wet weather and particularly on clayey soils, highlighting again that the time of construction is undertaken could be a way to mitigate some of the potential impacts of the construction process on natural carbon flows. Although it may not currently be possible to avoid the impact of compaction altogether, due to the requirement for heavy machinery to carry components and piledrivers to set the mounts in place, there may be a number of ways to reduce this disruption. Using lighter equipment for less time and in better weather conditions would likely reduce the impact of these processes. The size of the tracks may also have some impact, but there is also much uncertainty as to what this would be (larger tracks compact less but over greater areas, whereas narrow tracks will compact smaller areas, but at higher densities). Future versions of the SPCC should attempt to better resolve these impacts.

\subsection{Trenching}

There is also a need to excavate land area to install underground cables within solar parks (NSC, 2013). Although disturbing soil in general is typically bad for soil carbon (Dawson and Smith, 2007), discussions with industry professionals highlighted that best practice indicates soils should be separated and replaced as soon as are cables put in place, causing as minimal disturbance as possible. Assuming this best practice is followed, there should be relatively minimal impact on carbon flows, especially if aboveground biomass is maintained. If, however, soil is not separated effectively, or if trenches are left open for long, there is the potential for greater carbon impacts, including soil erosion due to flooding. Given the minimal impacts due 
to best practice, it was deemed suitable to not quantify this within this version of the SPCC, however future versions should attempt to include this impact if possible.

\subsubsection{Aboveground biomass}

Due to the huge importance of aboveground biomass in determining an area as a carbon source or sink (Milne and Brown, 1997), it was deemed that the inclusion of aboveground biomass was vital for the ecosystem carbon costs within the SPCC, particularly given the potential land use change. It is hoped that future versions of the SPCC may be able to make a more comprehensive review of the impact of aboveground biomass on overall carbon flows within a solar park, including the interaction with soil carbon.

\subsection{Complete land coverage}

The previously mentioned impacts of complete land coverage also apply to aboveground biomass carbon, notably due to the fact this will require the complete clearance of vegetation for the entirety of the solar park lifetime. Although given the small footprint of solar parks, this does not comprise a significant amount of carbon. However, inclusion could help inform some site designs, especially with the advent of bifacial panels and covering of the surface with reflective materials, such as gravel, in other nations.

\subsection{Shading}

The significant coverage of solar panels consolidates their importance within the SPCC, yet there is minimal literature on the potential implications. Armstrong et al. (2016) found that areas beneath panels had only $25 \%$ of the aboveground biomass of surrounding areas that were not shaded by panels. As this study was undertaken in the UK, and in the absence of any other data, it was included within the SPCC. Given this is based on one solar park design, improving understanding of other designs on vegetation biomass would be useful for future versions of the SPCC.

\subsection{Open Areas}

There is likely to be large areas of the park that are not over sailed by panels or completely covered. Therefore, potential changes in land cover (e.g., Arable to grassland) need to be considered. These changes in aboveground biomass may also be influenced by management 
practices, which will be discussed with operational impacts (see section 3.4.4.2). Although the carbon stored in aboveground biomass was likely to be less significant than that stored in soil when open areas are present, the importance of this aspect in determining the overall carbon source/sink status of an area (Milne and Brown, 1997) ensured that this was vital for consideration within a SPCC. Future versions of the SPCC should capture the dynamic nature of these flows within the wider context of the solar park.

\subsection{Construction Impacts}

There is a high likelihood that aboveground biomass carbon will be cleared or damaged during solar park construction. Although this could result in a temporary reduction in the levels of aboveground biomass within the solar park, contractual requirements to re-establish vegetation after the work may ensure that these reductions are minimal. Future versions of the SPCC may be able to quantify these changes and any dynamic future consequences they may hold for the land, but within this version it is sufficient to advise to reduce damage to aboveground biomass within construction where possible.

\subsubsection{Operational - Technological}

\subsubsection{Electricity generated/offset}

All of the four solar papers from the literature reviewed, as well as Nayak et al. (2010), make comparisons between the electricity generated during the solar park lifetime and the same quantity of electricity produced by alternative sources, commonly the grid supply. Including some quantification of this is crucial for an SPCC as this would provide the main source of negative emissions.

Producing an estimate of electricity generated is essential, ideally by the user providing an estimate based on commercial modelling software (typically PV Syst). Where this is not available, there is functionality within the SPCC to generate an estimate based on the DUKES capacity factors for the UK (GOV UK, 2020). The arrangement and tilt of panels may have an impact on the electricity generated within a solar park, though it should be assumed that the developer will consider these to maximise generation and as a result the DUKES average is sufficient. Degradation of electrical equipment decreases electrical output over the lifetime of a solar park (Antonanzas et al., 2019), making this a consideration for any new solar development. Many studies included this as a percentage reduction of electricity produced per year, with Jordan and Kurtz (2013) suggesting an average degradation rate of $0.5 \%$. It is 
hoped that future versions of the SPCC will be able to capture this reduction in electricity produced over the timescale of the park through a dynamic approach similar to Djomo and Ceulemans (2012) and Yang and Suh (2015), though this was not possible in the current version. This is unlikely to hold great significance to the accuracy of the current SPCC, as the DUKES capacity factor takes account of the average efficiency of UK solar parks, and so the degradation of this equipment should be captured within the figure, providing the most up to date information is used. Also, it was highlighted in discussions with industry professionals that the relative stability of the UK climate means equipment degradation is of less concern than in regions with temperature extremes.

Since solar PV equipment does not produce any new carbon emissions during electricity generation, it was deemed that any electricity produced can be considered as carbon credit, as this is offsetting grid electricity, which mostly uses fossil fuel sources. The magnitude of the carbon credit will rely on the current carbon intensity of the electricity it offsets; the greater the carbon intensity of the grid, the greater the offset. This is quantified within the SPCC, allowing for users to compare carbon benefits between different grid scenarios and the decarbonisation of electricity over time. The relevance of this has already been highlighted by Smith et al. (2014), which found that increasing uptake of renewables in the UK would reduce the capacity of new wind farms to create net carbon reductions.

It may be important to ensure that electricity produced is actually offsetting electricity generated by fossil fuel sources. If not, there is potential this will be wasted and could even be seen as a further carbon cost rather than a benefit. Matching electricity generation with peak demand, as well as the capability to store excess for times of need, are important factors here. Future versions of the SPCC may investigate these concerns further so that they can be quantified. This could include analysing the influence of tracking systems and how these can reduce the incidence of this problem, with electricity evenly spread throughout the day, rather than peaking during midday hours as with fixed axis systems. Potential benefits of tracking systems were highlighted in Beylot et al. (2014) which found that these could bring up to $32.5 \%$ increases in electricity generation for dual axis trackers, or $5 \%$ benefits for single axis trackers. This has not been included in this version of the SPCC due to current low uptake in the UK, though future versions may attempt to include this as their importance increases. 


\subsubsection{Backup generation}

Nayak et al. (2010) quantified backup generation in their wind farm carbon calculator, due to the intermittency of wind power. Since solar power also suffers from intermittency, with the inability to provide consistent power $24 / 7$ due to lack of sun at night and in periods of cloud cover, this was considered for the SPCC. Literature highlighted that grid energy demand for the UK does not correlate with solar panels output peaks. Since solar panels may not be producing any electricity when the demand peaks, and fossil fuel contributions are generally at their largest, their decarbonisation potential, without storage, may not be maximised. Quantifying the matching of the electricity produced by solar parks and grid demand within the SPCC, potentially including storage, would be very useful, but this was deemed out of scope for this current version of the SPCC. Nayak et al. (2010) suggests that when renewables are contributing less than $20 \%$ of the overall grid mix, there should be sufficient spare capacity from other sources, making this issue of relatively small concern.

It is possible to mitigate some of the mismatch between electricity supply and grid demand through energy storage or through running multiple renewable sources in tandem (Krauter and Rüther, 2004). There are several storage methods that are currently feasible, including compressed air or pump storage, and more notably battery storage, which can achieve efficiencies of over $80 \%$ (Nelson et al., 2014). Running several renewables in tandem can also reduce intermittency issues, as solar can be ran alongside wind (Nelson et al., 2014), or the power solar generates during the day can be used to pump water back up to hydroelectric dams (Krauter and Rüther, 2004; Ferroni and Hopkirk, 2016). Future versions of the SPCC may attempt to quantify the use of energy storage or backup supplies if these are critical to the function of the solar park, as these could incur significant carbon costs throughout the lifetime of the solar installation.

\subsubsection{Manufacture of replacement components}

Some studies factored in a replacement factor for components that would become unusable during the lifetime of the solar park (Mason et al., 2006). Although these could contribute significant emissions, it is likely that additional components would be purchased at the beginning of construction and so are included there. Components that degrade but do not need immediate replacement will be included within the degradation rate quantified within the SPCC. Discussions with developers suggested that the UK typically experiences much lower generation losses than many other EU countries, due to its relatively stable climate with low 
likelihood of extreme heats, which can damage electrical components. This will mean that replacement of components, as well as degradation rates, will not be highly significant, but should still be considered in future versions of the SPCC.

\subsubsection{Machinery \& resource use for maintenance}

There will be a continuous requirement for machinery use during the operation of the solar park to replace broken components and complete routine maintenance. Other than components replacement, which has already been discussed, panels must be cleaned of any dirt and overgrowing vegetation must be managed to maintain effective generation. These processes are highly important as any obstruction to panels will reduce efficiency and thus electricity generated by the site. The frequency of this maintenance is highly site dependent. Site owners may be able to minimise these costs by reducing areas of bare soil, by allowing grazing or by locating panels at sufficient distances from any potential tree coverage. These practices should minimise the operating carbon costs, though future versions of the SPCC may be toned to explore the associated carbon costs.

\subsubsection{Energy use during operation}

Depending on the setup of the solar park, there will be a number of energy requirements that must be met for the site to operate effectively. These may include tracking systems, lighting, heating/cooling of buildings for operators or electrical equipment with a specific operating temperature, and any other monitoring equipment on site. Any of these energy requirements can be seen as a reduction in the overall electricity provided to the grid if own generation is used, or a further carbon cost if grid electricity or other sources are employed. Although these were out of scope to be quantified within this version of the SPCC, due to the highly specific information required for this, future versions may be able to offer users the opportunity to provide this information.

\subsubsection{Operational - Ecosystem}

\subsubsection{Land Cover Change}

Although the impacts of the various land cover changes, including complete coverage, shading, open areas, and construction practices have already been discussed/quantified in the construction section of the SPCC, it is important to note that these carbon impacts primarily 
happen during the operation phase of the solar park. Difficulty including this as a dynamic process has prevented these from being included in the operation stage of the SPCC, though future versions should attempt to overcome this problem.

\subsubsection{Management practices}

Land management can have significant impacts on ecosystem carbon and thus will have consequences for the carbon sequestration of that area (Bradley et al., 2005). This was highlighted on many occasions throughout the literature search from bioenergy studies, and this was also relevant for the wind farm study of Nayak et al. (2010). The relevance of land management for solar park ecosystems was also highlighted by Randle-Boggis et al. (2020), consolidating the requirement for this to be included within the SPCC.

There may be the potential for carbon sequestration co-benefits of employing certain management practices within a solar park. For example, low intensity grazing can be used as an alternative to mowing, reducing machinery emissions as well as minimising ground compaction (Randle-Boggis et al., 2020). It was also demonstrated by Schuman et al. (1999) that grazing could increase topsoil carbon compared to control areas. Reseeding can also bring benefits to carbon flows and pollinators, particularly if it promotes biodiversity (Randle-Boggis et al., 2020). In Ma et al. (2000), it was demonstrated that sowing of switchgrass brought increases to soil carbon, compared to areas of fallow soil. Also, good drainage will prevent high levels of erosion by flowing water, particularly around the edges of panels where runoff is concentrated (Armstrong et al., 2016).

Biodiversity can have an impact on the overall soil carbon sequestration of an area (Chen et al., 2018). Biodiversity can also often be impacted by the construction of a solar park, through reduced habitat or differing migration patterns (Hernandez et al., 2014; Guerin, 2017). This can be reduced by including buffer areas around the solar park for biodiversity to recover (Guerin, 2017) or corridors can be introduced to reduce the impact of habitat fragmentation (Hernandez et al., 2014).

Information from the SPIES tool Randle-Boggis et al. (2020) may be used to supplement future versions of the SPCC in order to highlight practices that may lead to ecosystem carbon benefits or costs. This will most likely include the direction of benefits (e.g., positive or negative) rather than an exact quantification, due to difficulties in predicting the impact of a practice on such a dynamic system. In addition, Dawson and Smith (2007) suggested there should be limits to the benefits accrued from land management, since most land uses will have a soil carbon limit 
and, once met, better land management is unlikely to improve carbon storage further, meaning this should be considered in future attempts to quantify it.

\subsubsection{Decommissioning - Technological \\ 3.4.5.1 Machinery emissions from decommissioning}

Discussions with industry professionals highlighted that there is often a contractual obligation for all land to be returned to its original state at the end of the solar park life. This will likely require the use of heavy machinery, and thus the emissions of this should be considered. Although uncertainty as to the decommissioning practices has meant this has not been quantified within this version of the SPCC, it is quite possible that these emissions could be considered in a similar way to the construction emissions, with the time per each unit of equipment included. However, there is limited knowledge given solar parks have not yet reached their end of life in the UK.

\subsubsection{Transport to waste management facilities}

Transportation of the components from the solar site at the end of its life should ideally be incorporated. The significance of the emissions relating to this component will be directly related to the distance to the waste management facilities. Although this could be quantified in a similar method to that of the transportation emissions to site - as per standard emissions factors per tonne/ $\mathrm{km}$ - the uncertainty as to end of life practices of UK solar parks prohibits inclusion in this version of the SPCC. If the site owners are to decide the lifetime of the solar park should be extended and simply new replacement panels brought in, this cost could be significantly lower than if the whole facility was cleared. Equally, transporting old equipment to local recycling facilities rather than abroad will reduce emissions. This is more likely to be the case as UK solar parks reach their end of life due to the legal requirements of WEEE (EU, 2018) to effectively deal with electronic waste, meaning UK waste management firms will likely capitalise on this opportunity and open more facilities.

\subsubsection{Recycling}

Two of the studies included in the literature review highlighted the importance of end-of-life management of materials (Bogacka et al., 2017; Todde et al., 2018). Todde et al. (2018) highlighted how changes to European law since 2012 have made it compulsory to dispose of 
waste from solar parks effectively, and thus it is important that the environmental impact of this disposal is included in the SPCC. Bogacka et al. (2017) suggests there may be significant benefits if materials are recycled, with potential for negative emissions to be applied to new solar parks making use of recycled materials, particularly if these components are recycled locally. This study assumes that up to $90 \%$ of copper, solar glass, and silicon and up to $100 \%$ of aluminium were recovered. Furthermore, Beylot et al. (2014) assumed that $90 \%$ of the aluminium, $93 \%$ of the glass and $70 \%$ of the silicon from their study would actually be recycled at the end of their use. Although there is still much uncertainty as to how the end-of-life management of solar parks will occur in the UK, as it is still fairly distant in the future, recycling of electrical waste is already covered in several legal directives, including the EU'S WEEE (EU, 2018). As the material requirements of a solar park make up a significant proportion of the carbon emissions, any recycling of these components should be considered a benefit to its carbon flows. Therefore, it is important to include quantification of potential savings from recycling, as these are likely to be significant and are very likely to occur due to legal requirements. Future versions of the SPCC may quantify any emissions as a result of managing waste materials compared to the negative carbon emissions of recycling any components. However, current uncertainty for UK specifics meant that this was deemed out of scope for the current version of the SPCC.

\subsubsection{Decommissioning - Ecosystem}

\subsubsection{Soil}

\subsection{Impact on natural carbon processes of deconstruction activities}

Although the current uncertainty around decommissioning activities means that the impacts of deconstruction are not quantified, some discussion is still possible. As with the construction and operational ecosystem impacts, the decommissioning ecosystem impacts should be analysed with respect to how the soil carbon pools could be influenced, due to their high overall importance to terrestrial carbon cycling (Ostle et al., 2009). This may include any further damage to the land like soil compaction and erosion as a result of use of heavy machinery and removal of solar panels, assuming similar processes to construction are followed in reverse. However, assuming these similar activities are completed, impacts can be greatly reduced by following similar best practices to that advised for construction. 


\subsection{Land use change}

Nayak et al. (2010) considered decommissioning to be important within their study as the end of life of a wind farm could lead to renewal of the previous land use. This was particularly important due to the focus of the study being on peatland areas, which may not be as relevant for solar parks due to the low likelihood for these to be located in these areas. Current uncertainty as to whether further land use change would occur at the end of life of a solar park has meant that this component is not quantified within the SPCC. However, future versions could aim to include this if more information is available on common end of life practices.

\subsubsection{Aboveground biomass}

\subsection{Impact on natural carbon processes of deconstruction activities}

Similarly to construction processes, there is potential that use of heavy machinery will result in the clearance of aboveground biomass during the deconstruction process. There is potential that this will only be temporary, and the fact that new access tracks should not need to be constructed may ensure that this impact is smaller than that of the solar park construction. Again, reducing clearance of aboveground biomass where possible is advised.

\subsection{Land use change}

Land use change could bring significant benefits or reductions to aboveground biomass carbon, depending on what the land is reverted to. These impacts are not quantified, but could be considered in future versions of the SPCC when there is better understanding of how the land will be used post solar park decommissioning. This could include considerations of the differential valuation of carbon over time, with carbon savings in current values more highly valued than promises of carbon savings tomorrow, in order to better mitigate the impacts of climate change (Yang and Suh, 2015).

\subsubsection{Carbon Payback Time}

Carbon Payback time is the time taken for a renewable system to offset the lifecycle emissions of the installation, through renewable energy generation (Murray and Petersen, 2004). This is necessary within the SPCC to indicate whether a solar development is a net carbon cost (if payback time is longer than the lifetime of the solar park) or a net carbon benefit (if payback time is within the lifetime of the solar park). This can act as a supplement to the decisionmaking process, as a shorter payback time indicates likely higher carbon reductions and thus 
a more desirable setup, whereas solar parks with payback times longer than the lifetime of the solar park should be considered carefully before construction. Carbon payback is a consideration included by a vast array of carbon calculators, from bioenergy (Gibbs et al., 2008) and wind (Nayak et al., 2010) to solar (Todde et al., 2018; Antonanzas et al., 2019; Pinto et al., 2020), further highlighting the importance within the SPCC. The current version employs a simple calculation using a similar method to Todde et al. (2018), with the total carbon emissions relating to the net carbon release of technological and ecosystem components and the yearly carbon savings only referring to the offset carbon from electricity generation. This method is suitable given the current approach of quantifying technological and ecosystem carbon flows as a single lifetime impact rather than a yearly flow. If future versions of the SPCC are able to capture the dynamic nature of ecosystem carbon flows, these could well be included alongside electricity generated within the yearly carbon offset.

\subsubsection{Critical research needs}

\subsubsection{Time element}

Temporal dynamics were only included in two of the 27 papers reviewed to develop the SPCC (Djomo and Ceulemans, 2012; Yang and Suh, 2015). Djomo and Ceulemans (2012) highlighted the importance of different timescales when modelling natural carbon flows, and Yang and Suh (2015) used this feature to analyse the impacts of technological improvements and timing of emissions on carbon payback time. Within the SPCC, this would not only make projections for natural carbon flows more realistic, due to the non-linear nature of carbon cycling following land use change (Soussana et al., 2004), but would also allow for improvements in technology which has already been exponential over recent years and so is likely to continue into the future. This could also be useful for displaying changes to the carbon intensity of grid electricity over time, as decarbonisation of the UK grid could lead to changes in the ability of solar parks to act as a carbon offset over time (Smith et al., 2014). Transparency with this feature would be required, to make it possible for the user to decide how best to use this function, turning it off if necessary and even allowing for discounting of future emissions savings if desired. Although this feature was not applied to this version of the SPCC, the benefits of its application to other carbon calculators highlighted how this would be a desirable feature for future versions. 


\subsubsection{Data Gaps}

The SPCC could be vastly improved by a greater availability of data. A number of sources that were either unavailable for access or simply do not exist are highlighted here, with expectation that future versions may be able to benefit from these as and when they become available:

- Standard emissions for PV components (panels, mounts, cabling, inverters, switchgear/transformers)

- Databases for emissions values (e.g., (Ecolnvent, ND)

- Soil and aboveground biomass carbon data specific to solar parks (including shading and complete coverage)

- Information for carbon dynamics

- Component emissions due to country of origin

\subsection{Conclusion}

The increase in land use change for solar parks in the UK, combined with legal obligations to reduce carbon emissions, has meant that quantification of solar park carbon impacts is of vital importance. Providing a standardised approach to achieving this that does not neglect ecosystem services and natural capital should be extremely desirable to policymakers and industry users alike. This chapter aimed to produce an idealised framework for a solar park carbon calculator (SPCC) and to quantify a range of technological and ecosystem carbon flows throughout the lifecycle of a solar park. A preliminary SPCC that utilises the sparse information in this area based on literature, industry reports and discussions with professionals is provided, before recommendations are made for future updated versions. For example, creating a more dynamic approach to both estimating ecosystem carbon costs and electricity generation over time (due to depreciation) should add much value to the estimates provided. Also, increased access to novel industry information should reduce uncertainty, whilst ensuring estimates are more applicable to end users. Reducing uncertainty in estimates, whilst increasing application to industry activities, should be of the highest importance to future SPCC versions, as this will bring the highest benefits to achieving net zero carbon emissions targets, whilst minimising impacts to ecosystem services and natural capital. 


\subsection{Discussion \& Conclusions}

\subsection{Challenges with quantification of carbon stocks and flows}

Rapid improvements in the economic feasibility of solar PV in recent years has led to fast uptake of all renewables (IEA, 2020). Although PV technology has been around for many years, deployment as solar parks is relatively new and thus potential ecological impacts are poorly resolved. The recent rapid uptake of solar technology, and thus increase in solar parks, means that quantification of impacts is vital. There is missing and less certain technological and ecological information within the SPCC, as limited studies have focused specifically on solar parks. Given that much technical knowledge (i.e., panel carbon emissions) is consistent regardless of deployment means, there is more uncertainty related to ecosystem carbon costs. This lack of information means that quantification has either not been possible or has been less accurate than desirable. However, these knowledge gaps have been highlighted in the framework, so that these can be quantified at a later date as knowledge improves.

\subsubsection{Knowledge gaps}

Whilst there were some knowledge gaps within the 'specific' information for the construction phase of technological components (e.g., inverters), the inclusion of the 'generic' approach meant that most technological carbon costs were covered within the SPCC to some extent, as this included emissions data from construction to end-of-life management (Mason et al., 2006). On the other hand, there were far more knowledge gaps for the ecosystem components, with large information gaps when it came to quantifying carbon stocks or flows for construction activities, management, or end-of-life impacts on hosting ecosystems.

The greater number of ecosystem knowledge gaps compared to technological may be due to the comparative scale of carbon flows between these components throughout the different stages of the life cycle of a solar park. Even with recent improvements in manufacturing techniques, producing the technological components for solar PV installations requires high quantities of energy, and thus carbon, with panel production making up to $80 \%$ of the embedded energy (Todde et al., 2018). With such high carbon flows, there is perhaps less concern for the ecosystem impacts as these are seen as less important in terms of quantities of GHGs due to their long-time scales and difficulties in attributing changing emissions to any single cause (Smith, 2014).

Whilst Nayak et al. (2010) demonstrated significant ecosystem carbon flows associated with wind farm development, their study focussed on the carbon rich peatland soils of Scotland. 
Within the UK, no solar parks have been built on upland peatlands due to the low incidence of solar radiation and poor soil stability (Palmer et al., 2019). Consequently, the majority of new solar parks in the UK have been developed on arable land, with arable land containing less than half of the carbon per ha than peatlands (Ostle et al., 2009). This may be a future consideration however, with the first applications for solar parks on peatlands in progress in Scotland (Lempriere, 2021). The Nayak et al. (2010) findings highlight the potential importance of quantifying solar park impacts on peatlands. However, given the urgency to reach net zero targets, policy focus on land carbon uptake, and increasing deployment of solar parks, it is increasingly important to capture the impacts and identify means by which to increase carbon sequestration, regardless of the ecosystem type they are located on.

\subsubsection{Uncertainty with information}

Estimates of the ecosystem carbon flows are provided within the SPCC. However, due to the scarcity of literature in this area, there is a certain level of uncertainty surrounding these estimates, which must be considered when applied practically. Soil carbon and aboveground biomass carbon rates both make use of average values for land cover classifications according to (Morton et al., 2020), yet these values will vary depending on a number of local climate factors, such as temperature, humidity and precipitation (Soussana et al., 2004).

Although there is always likely to be a notable base-level of uncertainty when it comes to estimating ecosystem carbon flows, due to the dynamic nature of grassland carbon cycling (Smith, 2014), this is not necessarily the case when it comes to technological carbon flows. Making use of emissions figures for site specific components from manufacturers data sheets should provide highly accurate carbon flows for the solar park. This will greatly reduce the uncertainty associated with employing the 'generic' approach within the SPCC by ensuring that estimates are based on site specifics.

Irrespective of the uncertainty with some components, and missed components, the SPCC is still a much more comprehensive carbon tool than is typically applied to traditional fossil fuel sources. This is due to the fact that currently fossil fuel developments don't include the emissions due to facilities production or land use change in overall emissions figures, so the comparison between renewable and non-renewable sources is problematic at best (Nayak et al., 2010). If non-renewable sources were to also include the emissions for this equipment as well as land use impacts, it is likely that there would be a higher overall grid emissions mix and thus a quicker payback time for solar PV. 


\subsection{Using the tool to minimise carbon emissions}

Searching for a 'perfect' solution to climate change in which goals for carbon reductions are met and there are no impacts to hosting ecosystems may be an unattainable goal. Instead, a more practical approach may be to minimise the impacts whilst maximising carbon reductions. Below, suggestions are provided to achieve a quicker carbon payback time based on recommendations for carbon cost reductions within the technological and ecosystem components.

\subsubsection{Recommendations for technological reductions}

Given the significance of the technological costs to the overall carbon flows within the SPCC, it is important for developers to consider options to reduce carbon emissions wherever possible.

\subsubsection{Utilise tech from low carbon grids}

Nelson et al. (2014) suggested that the grid mix of the country producing the PV components would influence the associated carbon emissions of those components. Evidence for this was seen within the SPCC for panels (de Wild-Scholten, 2013) and inverters (SMA, 2018), highlighting how this could be relevant to all other components if data were available. With this in mind, it is highly important to make use of components produced using low carbon grid energy, particularly for components such as solar panels which require an energy intensive process. Therefore, making use of renewable sources of energy to fabricate components will result in lower net carbon emissions and thus quicker payback time. However, transportation requirements also need to be considered when identifying potential sources of components, particularly if employing these low-carbon components requires utilisation of high carbon transportation such as air transport (Time for Change, ND).

\subsubsection{Manufacturing company standards}

Where it is not financially (or otherwise) viable to acquire components from sources utilising low carbon energy, industry standards may be the next best method of reducing carbon emissions of components purchased. Although emissions reporting is not currently standardised between companies, there has still been some effort to compare environmental 
information between solar PV producers in the form of the STVC solar scorecard (SVTC, 2019). This compares many of the top producers of solar PV modules and ranks these companies based on factors such as greenhouse gas emissions and use of toxic materials, as well as other factors such as worker satisfaction (SVTC, 2019). Purchasing equipment from those ranked highly on this scorecard should indicate a lower carbon cost and thus lower carbon payback time.

\subsubsection{Technological advancements}

The use of technologies that maximise electricity generation are likely to bring reductions to carbon payback times, all other things being equal. The use of bifacial panels may become more widespread as the cost of the technology continues to reduce, and assuming there is not a greater carbon cost, these should bring generation benefits (Luque et al., 1985). Tracking systems on the other hand may bring new carbon costs due to additional components required (Antonanzas et al., 2019), but the benefits for electricity production (Beylot et al., 2014), as well as improving the supply curve (Helwa et al., 2000), could lead to benefits outweighing any disadvantages. Whilst the use of very low carbon mounting structures such as wood (Beylot et al., 2014) may not be feasible anytime soon, using recycled materials in the mounting structures is feasible and thus should be considered (Bogacka et al., 2017; Todde et al., 2018). The large material requirements for solar park mounting structures and fencing (Szilágyi and Gróf, 2020) means that even a small increase in recycled materials could bring large carbon savings (Bogacka et al., 2017; Todde et al., 2018).

\subsubsection{Integrating with other renewables and storage}

Even if low emissions components are utilised in constructing a solar park, and the park is running at full efficiency, there is still the problem of ensuring that the electricity generated is being utilised effectively. If electricity is being wasted due to poor matching of supply to demand, carbon benefits will not be realised, as there will be a demand from traditional sources in the grid to plug gaps (Krauter and Rüther, 2004). This is where energy storage or running many renewables in tandem becomes most important. If either of these methods are to be employed in order to avoid electrical losses, their carbon impact must also be considered. Battery storage is a common favourite, due to high efficiencies of up to $80 \%$ (Nelson et al., 2014), but these also have high demand for materials, particularly due to replacements which must occur three or more times in a solar park's lifetime (Nelson et al., 
2014). Not only is there potential for these materials to have high carbon costs associated with production, but if the waste is not managed effectively, there is also potential for significant other environmental impacts through toxic waste produced (Bogacka et al., 2017). Compressed gas storage can avoid some of these environmental impacts as an alternative energy storage method. However, the lower efficiency may mean that larger areas are required to meet energy demands (Nelson et al., 2014). Running multiple renewable energy technologies in tandem can be a useful strategy to reduce intermittency and thus wastage of the renewable energy produced (Krauter and Rüther, 2004; Ferroni and Hopkirk, 2016). This could include using other renewables in times of low generation (i.e., employ biomass boilers at night), or simply run two renewables at the same time (solar energy to pump water back up to hydroelectric reservoirs). The combination of solar and hydro has been the most prominent example up to now, but there is likelihood that other methods could be expanded in the future (Krauter and Rüther, 2004; Ferroni and Hopkirk, 2016).

\subsubsection{Recommendations for ecological reductions}

Given the uncertainty of estimates for ecological carbon impacts of solar parks, it is important to reduce these impacts wherever possible, with the hope of promoting benefits to ecosystem services and natural capital. Recommendations of how this can be achieved are provided below.

\subsubsection{Avoid areas of high ecosystem carbon}

The terrestrial carbon stored in an area of land before solar park construction will determine the net carbon change once development has occurred. This was highlighted by Nayak et al. (2010), which made areas of Scottish peatlands the focus of their study, due to high quantities of carbon stored these areas. Although this may not be as much of a concern for solar parks with the low likelihood of solar parks being developed on upland peatland areas due to typically low solar irradiance (Palmer et al., 2019) - the carbon stored in the land area should still be considered, especially in carbon rich mineral soil areas.

\subsubsection{Best practice construction}

For areas where solar parks are developed, the use of best practice wherever possible will have a significant impact on the overall effort to reduce ecosystem carbon impacts from 
activities within a solar park. This will perhaps be most relevant to the construction and decommissioning phases of the park, whereby if these practices are followed effectively, the carbon impacts should be reduced. This will include practices such as careful placement of the construction compound to reduce footprint and separation of soil layers in any situations that excavation cannot be avoided (NSC, 2013).

\subsubsection{Good land management}

Land management, for example allowing grazing (Schuman et al., 1999) or selective seeding (Ma et al., 2000), of solar parks can have notable impacts on carbon sequestration for grassland areas. More specifically to solar parks, following recommendations from expert tools such as SPIES (Randle-Boggis et al., 2020) can improve the carbon sequestration of the development area during its lifetime. Also, reducing resource and machinery use when management activities require these (panel cleaning) can minimise any further carbon impacts and thus reduce carbon payback time.

\subsubsection{Extend solar park lifetimes}

Assuming the technology degrades at a fairly low rate due to the lack of extreme temperatures in the UK, equipment may still be operating effectively at the end of the originally agreed park lifetime. Assuming no significant changes in the capacity of the area to host a solar park (e.g., lack of land ownership), it may well be suitable to extend the life of the park, even if this means replacing some components for newer, more efficient ones. Not only will this reduce the requirements for new materials as a great deal of the same infrastructure (including mounts) can be reused, this can also prevent further land use change associated with building a replacement park in another location, conserving habitats, and leaving ecosystem carbon stores undisturbed. Due to no UK solar parks having currently reached their decommissioning stage, there is still much uncertainty as to whether this practice will be feasible. However, the potential reductions this could bring for carbon payback times indicates this should be considered.

\subsection{Future tool development}

A comprehensive approach has been taken in developing the current SPCC in order to ensure that a range of ecosystem and technological carbon costs are covered throughout the lifecycle 
of the park. However, a number of aspects could not be included in the current SPCC, and as a result, recommendations that could improve future versions are provided below.

\subsubsection{Refining input data}

A higher availability of input data should vastly improve the reliability of estimates provided by the SPCC. Although improvements will be minimal if the user is already electing to input their park-specific information into the SPCC, there is still room for improvements when 'suggested' or 'generic' options are used. Replacing information from Mason et al. (2006) with UK specific data when these become available may go some way in improving the application of results from the 'generic' approach of the SPCC. Also, utilising database values from popular LCA sources such as Ecolnvent (ND) for 'suggested' technological carbon values should improve the reliability of these estimates. Including up to date soil and aboveground biomass carbon data from UK studies at solar parks should be beneficial for ecosystem carbon costs, particularly if this includes a number of previous and current land uses. Furthermore, including quantification of land management impacts on solar parks, as opposed to the directional impacts currently suggested by Randle-Boggis et al. (2020), should allow SPCC estimates to better aid management decisions. Inputting decommissioning information, for both technological and ecological components, as these become available, should also improve the estimates provided by the SPCC.

\subsubsection{Adding a dynamic temporal component}

Although this was out of scope for the current SPCC, providing dynamic estimates for carbon impacts would provide added value to future versions. This would include allowing for better estimates of yearly electricity production due to technology depreciation according to Jordan and Kurtz (2013) and changes to grid mix over time according to DECC (2019). This could also significantly improve ecosystem carbon flows, with a dynamic approach allowing for the estimation of carbon accumulation in soil and aboveground biomass over the park lifetime, capturing the asymmetric and non-linear nature of these flows (Soussana et al., 2004). Finally, this could also allow for emissions discounting to be applied within the SPCC, with future offset values lower than present emissions (Emmerling et al., 2019). This method has frequently been seen in integrated assessment modelling to represent the importance of avoiding unknown tipping points through emissions reductions, rather than relying on emissions offsets which may never actualise (Emmerling et al., 2019). This would vastly improve the carbon 
payback time feature of the SPCC, representing the benefits of minimising carbon costs throughout the park's lifetime.

\subsubsection{Extending beyond carbon}

Although carbon is certainly a very important environmental consideration with current targets for climate change and achieving net zero carbon emissions, there are several other potential ecosystem impacts of solar parks. For example, the EU environmental foot-printing regulations recommend the inclusion of acidification, freshwater ecotoxicity and ionising radiation as potential impacts caused by solar park development (EU, 2013). These indicators, among others, were quantified within Szilágyi and Gróf (2020), highlighting the relevance of all of these to modern solar parks, in addition to carbon costs. Future work could include broadening the scope of the SPCC to include such other ecosystem impacts, thus ensuring the broader environmental sustainability of low carbon electricity produced by solar parks.

\section{Conclusions}

With the growing need to achieve a wide array of land management targets, alongside efforts to reduce carbon emissions, quantifying the potential ecosystem and technological carbon costs of solar parks is vitally important. This study reviewed current attempts to capture carbon costs of renewable energy technologies through a systematic review of existing carbon calculators, before suggesting an idealised framework of how this could be applied to solar parks. The solar park carbon calculator (SPCC) that has resulted from this has been substantiated through existing literature, industry recommendations and reports and government guidance. Recommendations as to how the carbon payback time can be reduced are provided, including utilising components produced using low-carbon grid energy and avoiding the siting of solar parks on areas of high soil carbon (e.g., peatlands). The current SPCC provides a more comprehensive approach than that expected of traditionally nonrenewable energy supplies, but improvements can still be made, including the addition of a dynamic temporal aspect to account for the non-linear carbon flows of soil carbon, as well as emissions discounting. Ultimately, better understanding of the carbon costs of solar parks may assist in efforts to achieve net zero targets. 


\section{List of references}

Antonanzas, J., Arbeloa-Ibero, M. \& Quinn, J. C. 2019. Comparative Life Cycle Assessment of Fixed and Single Axis Tracking Systems for Photovoltaics. Journal of Cleaner Production, $240 \leq$ Go to ISI $>$ ://WOS:000487936100043.

Arcelormittal. ND. Steel Is the Power Behind Renewable Energy [Online]. Available: https://corporate.arcelormittal.com/media/case-studies/steel-is-the-power-behindrenewable-energy [Accessed 13/05/2021.

Armstrong, A., Ostle, N. J. \& Whitaker, J. 2016. Solar Park Microclimate and Vegetation Management Effects on Grassland Carbon Cycling. Environmental Research Letters, 11(7), 074016.

Armstrong, A., Waldron, S., Whitaker, J. \& Ostle, N. J. 2014. Wind Farm and Solar Park Effects on Plant-Soil Carbon Cycling: Uncertain Impacts of Changes in Ground-Level Microclimate. Global change biology, 20(6), 1699-1706.

Barron-Gafford, G., Minor, R., Brooks, A., Pavao-Zuckerman, M. \& Cronin, A. 2016. The Photovoltaic Heat Island Effect: Larger Solar Power Plants Increase Local Temperatures (Open Access: $\underline{\text { Http://Www.Nature.Com/Articles/Srep35070). }}$. Scientific Reports, 6, 35070.

Beylot, A., Payet, J., Puech, C., Adra, N., Jacquin, P., Blanc, I. \& Beloin-Saint-Pierre, D. 2014. Environmental Impacts of Large-Scale Grid-Connected Ground-Mounted Pv Installations. Renewable Energy, 61, 2-6.

Boardman, J. 2013. Soil Erosion in Britain: Updating the Record. Agriculture, 3(3), 418-442 https://www.mdpi.com/2077-0472/3/3/418.

Bogacka, M., Pikoń, K. \& Landrat, M. 2017. Environmental Impact of Pv Cell Waste Scenario. Waste Management, 70, 198-203 http://www.sciencedirect.com/science/article/pii/S0956053X17306712.

Bp 2019. Bp Statistical Review of World Energy 2019. https://www.bp.com/content/dam/bp/businesssites/en/global/corporate/pdfs/energy-economics/statistical-review/bp-statsreview-2019-full-report.pdf.

Bradley, R. I., Milne, R., Bell, J., Lilly, A., Jordan, C. \& Higgins, A. 2005. A Soil Carbon and Land Use Database for the United Kingdom. Soil Use and Management, 21(4), 363-369 https://onlinelibrary.wiley.com/doi/abs/10.1079/SUM2005351.

Burke, M. J. \& Stephens, J. C. 2018. Political Power and Renewable Energy Futures: A Critical Review. Energy Research \& Social Science, 35, 78-93 http://www.sciencedirect.com/science/article/pii/S2214629617303468.

Calciu, I., Vizitiu, O. \& Simota, C. 2017. Greenhouse Gas Emissions from Sunflower Cultivation for Biofuels and Biodiesel Production. Agrolife Scientific Journal, 6(2), 27-32 $\leq$ Go to |S|>://WOS:000423885500004.

Chen, S., Wang, W., Xu, W., Wang, Y., Wan, H., Chen, D., Tang, Z., Tang, X., Zhou, G. \& Xie, Z. 2018. Plant Diversity Enhances Productivity and Soil Carbon Storage. Proceedings of the National Academy of Sciences, 115(16), 4027-4032.

Collins, A., Coughlin, D., Miller, J. \& Kirk, S. 2015. The Production of Quick Scoping Reviews and Rapid Evidence Assessments: A How to Guide.

Committee on Climate Change 2019. Net Zero - Technical Report. https://www.theccc.org.uk/wp-content/uploads/2019/05/Net-Zero-Technicalreport-CCC.pdf.

Dawson, J. J. C. \& Smith, P. 2007. Carbon Losses from Soil and Its Consequences for Land-Use Management. Science of The Total Environment, 382(2), 165-190 http://www.sciencedirect.com/science/article/pii/S0048969707003695. 
De Wild-Scholten, M. J. 2013. Energy Payback Time and Carbon Footprint of Commercial Photovoltaic Systems. Solar Energy Materials and Solar Cells, 119, 296-305 http://www.sciencedirect.com/science/article/pii/S0927024813004455.

Decc 2019. Valuation of Energy Use and Greenhouse Gas Emissions for Appraisal and Evaluation.Guidance Table 1-19: Supporting the Tool Kit and the Guidance.Table1: Electricity Emissions Factors to 2100. https://www.gov.uk/government/publications/valuation-of-energy-use-andgreenhouse-gas-emissions-for-appraisal: Department of Energy and Climate Change.

Defra 2020. Agriculture Bill. In: DEPARTMENT FOR ENVIRONMENT FOOD \& RURAL AFFAIRS 2020 (ed.).

https://assets.publishing.service.gov.uk/government/uploads/system/uploads/attac hment data/file/930771/2020-10-28 RPC-DEFRA-5019 Agriculture Bill.pdf: UK GOV.

Desideri, U., Proietti, S., Zepparelli, F., Sdringola, P. \& Bini, S. 2012. Life Cycle Assessment of a Ground-Mounted 1778kwp Photovoltaic Plant and Comparison with Traditional Energy Production Systems. Applied Energy, 97, 930-943 https://www.sciencedirect.com/science/article/pii/S030626191200061X.

Djomo, S. N. \& Ceulemans, R. 2012. A Comparative Analysis of the Carbon Intensity of Biofuels Caused by Land Use Changes. Global Change Biology Bioenergy, 4(4), 392$407 \leq$ Go to $|S|>$ ://WOS:000304810100003.

Dupraz, C., Marrou, H., Talbot, G., Dufour, L., Nogier, A. \& Ferard, Y. 2010. Combining Solar Pvpanels and Food Crops for Optimising Land Use: Towards New Agrivoltaic Schemes. Renew. Energy, 36, 2725-2732.

Ecoinvent. ND. The Ecoinvent Database [Online]. Available: https://www.ecoinvent.org/database/database.html [Accessed 22/06/2021.

Electricity Info. ND. Real Time British Electricity Fuel Mix [Online]. Available: https://electricityinfo.org/real-time-british-electricity-supply/ [Accessed 22/06/2021.

Emmerling, J., Drouet, L., Wijst, K.-I. V. D., Vuuren, D. V., Bosetti, V. \& Tavoni, M. 2019. The Role of the Discount Rate for Emission Pathways and Negative Emissions. Environmental Research Letters, 14(10), 104008 http://dx.doi.org/10.1088/17489326/ab3cc9.

Emmett, B., Reynolds, B., Chamberlain, P., Rowe, E., Spurgeon, D., Brittain, S., Frogbrook, Z., Hughes, S., Lawlor, A. \& Poskitt, J. 2010. Countryside Survey: Soils Report from 2007.

Environment Agency 2019. The State of the Environment https://www.gov.uk/government/publications/state-of-the-environment/summarystate-of-the-environment-soil.

Eu 2013. Recommendation 2013/179/Eu on the Use of Common Methods to Measure and Communicate the Life Cycle Environmental Performance of Products and Organisations. EUR-Lex, http://data.europa.eu/eli/reco/2013/179/oj.

Eu 2018. Directive 2012/19/Eu of the European Parliament and of the Council of 4 July 2012 on Waste Electrical and Electronic Equipment (Weee) EUR-Lex, http://data.europa.eu/eli/dir/2012/19/2018-07-04.

Ferroni, F. \& Hopkirk, R. J. 2016. Energy Return on Energy Invested (Eroei) for Photovoltaic Solar Systems in Regions of Moderate Insolation. Energy Policy, 94, 336-344 http://www.sciencedirect.com/science/article/pii/S0301421516301379.

First Fence. ND. 2.0m High 'V' Mesh Security Fencing [Online]. Available: https://www.firstfence.co.uk/2-0m-high-v-mesh-security-fencing [Accessed 05/06/2021.

Fraunhofer Institute for Solar Energy Systems 2020. Photovoltaics Report. https://www.ise.fraunhofer.de/content/dam/ise/de/documents/publications/studie s/Photovoltaics-Report.pdf. 
Frischknecht, R., Heath, G., Raugei, M., Sinha, P. \& De Wild-Scholten, M. 2016. Methodology Guidelines on Life Cycle Assessment of Photovoltaic Electricity. National Renewable Energy Lab.(NREL), Golden, CO (United States).

Frischknecht, R., Itten, R., Sinha, P., De Wild-Scholten, M., Zhang, J., Fthenakis, V., Kim, H., Raugei, M. \& Stucki, M. 2015. Life Cycle Inventories and Life Cycle Assessment of Photovoltaic Systems. International Energy Agency (IEA) PVPS Task 12, Report T12, 4, 2015.

Frischknecht, R., Itten, R., Sinha, P., De Wild-Scholten, M., Zhang, J., Fthenakis, V., Kim, H., Raugei, M. \& Stucki, M. 2020. Life Cycle Inventories and Life Cycle Assessment of Photovoltaic Systems. International Energy Agency (IEA) PVPS Task 12, Report T12, 4, 2015.

Gagnon, L., Bélanger, C. \& Uchiyama, Y. 2002. Life-Cycle Assessment of Electricity Generation Options: The Status of Research in Year 2001. Energy Policy, 30(14), 1267-1278 https://www.sciencedirect.com/science/article/pii/S0301421502000885.

Gerbinet, S., Belboom, S. \& Léonard, A. 2014. Life Cycle Analysis (Lca) of Photovoltaic Panels: A Review. Renewable and Sustainable Energy Reviews, 38, 747-753 http://www.sciencedirect.com/science/article/pii/S136403211400495X.

Gibbs, H. K., Johnston, M., Foley, J. A., Holloway, T., Monfreda, C., Ramankutty, N. \& Zaks, D. 2008. Carbon Payback Times for Crop-Based Biofuel Expansion in the Tropics: The Effects of Changing Yield and Technology. Environmental research letters, 3(3), 034001.

Gov Uk. 2019. Uk Becomes First Major Economy to Pass Net Zero Emissions Law [Online]. https://www.gov.uk/government/news/uk-becomes-first-major-economy-to-passnet-zero-emissions-law. 2021].

Gov Uk 2020. Digest of Uk Energy Statistics (Dukes): Renewable Sources of Energy. DUKES chapter 6: statistics on energy from renewable sources.

https://www.gov.uk/government/statistics/renewable-sources-of-energy-chapter-6digest-of-united-kingdom-energy-statistics-dukes: Department for Business, Energy \& Industrial Strategy.

Guerin, T. 2017. A Case Study Identifying and Mitigating the Environmental and Community Impacts from Construction of a Utility-Scale Solar Photovoltaic Power Plant in Eastern Australia. Solar Energy, 146, 94-104 http://www.sciencedirect.com/science/article/pii/S0038092X17301135.

Hassanpour Adeh, E., Selker, J. S. \& Higgins, C. W. 2018. Remarkable Agrivoltaic Influence on Soil Moisture, Micrometeorology and Water-Use Efficiency. PLOS ONE, 13(11), e0203256 https://doi.org/10.1371/journal.pone.0203256.

Helwa, N. H., Bahgat, A. B. G., El Shafee, A. M. R. \& El Shenawy, E. T. 2000. Maximum Collectable Solar Energy by Different Solar Tracking Systems. Energy Sources, 22(1), 23-34 https://doi.org/10.1080/00908310050014180.

Hernandez, R. R., Armstrong, A., Burney, J., Ryan, G., Moore-O'leary, K., Diédhiou, I., Grodsky, S. M., Saul-Gershenz, L., Davis, R., Macknick, J., Mulvaney, D., Heath, G. A., Easter, S. B., Hoffacker, M. K., Allen, M. F. \& Kammen, D. M. 2019. Techno-Ecological Synergies of Solar Energy for Global Sustainability. Nature Sustainability, 2(7), 560568 https://doi.org/10.1038/s41893-019-0309-z.

Hernandez, R. R., Easter, S. B., Murphy-Mariscal, M. L., Maestre, F. T., Tavassoli, M., Allen, E. B., Barrows, C. W., Belnap, J., Ochoa-Hueso, R., Ravi, S. \& Allen, M. F. 2014. Environmental Impacts of Utility-Scale Solar Energy. Renewable and Sustainable Energy Reviews, 29, 766-779 http://www.sciencedirect.com/science/article/pii/S1364032113005819.

Hillier, J., Walter, C., Malin, D., Garcia-Suarez, T., Mila-I-Canals, L. \& Smith, P. 2011. A FarmFocused Calculator for Emissions from Crop and Livestock Production. Environmental Modelling \& Software, 26(9), 1070-1078. 
Ice. 2019. The Inventory of Carbon and Energy [Online].

https://circularecology.com/embodied-carbon-footprint-database.html.

lea 2019. World Energy Outlook 2019. https://www.iea.org/reports/world-energy-outlook$\underline{2019}$.

lea 2020. Renewables 2020. https://www.iea.org/reports/renewables-2020.

Ipbes 2019. Global Assessment Report on Biodiversity and Ecosystem Services Bonn, Germany:: Intergovernmental Science-Policy Platform on Biodiversity and Ecosystem Services.

Jäger-Waldau, A. 2006. European Photovoltaics in World Wide Comparison. Journal of NonCrystalline Solids, 352(9), 1922-1927 https://www.sciencedirect.com/science/article/pii/S0022309306002092.

Jinkosolar 2018. Ehs Report 2018. https://jinkosolar.eu/en/company/sustainability.html. Jonker, J. G. G., Junginger, M. \& Faaij, A. 2014. Carbon Payback Period and Carbon Offset Parity Point of Wood Pellet Production in the South-Eastern United States. Global Change Biology Bioenergy, 6(4), 371-389 $\leq$ Go to $|S|>: / / W O S: 000337672700007$.

Jordan, D. C. \& Kurtz, S. R. 2013. Photovoltaic Degradation Rates-an Analytical Review. Progress in Photovoltaics: Research and Applications, 21(1), 12-29 https://onlinelibrary.wiley.com/doi/abs/10.1002/pip.1182.

Krauter, S. \& Rüther, R. 2004. Considerations for the Calculation of Greenhouse Gas Reduction by Photovoltaic Solar Energy. Renewable energy, 29(3), 345-355.

Lal, R. 2004. Soil Carbon Sequestration Impacts on Global Climate Change and Food Security. science, 304(5677), 1623-1627.

Leccisi, E., Raugei, M. \& Fthenakis, V. 2016. The Energy and Environmental Performance of Ground-Mounted Photovoltaic Systems-a Timely Update. Energies, 9(8), 622 https://www.mdpi.com/1996-1073/9/8/622.

Lempriere, M. 2021. Scottish Power to Build 40mw of Solar to Help Fuel Green Hydrogen for Scotland [Online]. Available:

https://www.solarpowerportal.co.uk/news/scottishpower to build $40 \mathrm{mw}$ of solar to help fuel green hydrogen for scotla [Accessed 28/06/2021.

Luque, A., Lorenzo, E., Sala, G. \& López-Romero, S. 1985. Diffusing Reflectors for Bifacial Photovoltaic Panels. Solar Cells, 13(3), 277-292 https://www.sciencedirect.com/science/article/pii/0379678785900213.

Ma, Z., Wood, C. \& Bransby, D. I. 2000. Soil Management Impacts on Soil Carbon Sequestration by Switchgrass. Biomass and bioenergy, 18(6), 469-477.

Malca, J., Freire, F. \& leee 2011. Capturing Uncertainty in Ghg Savings and Carbon Payback Time of Rapeseed Oil Displacing Fossil Diesel in Europe. 2011 leee International Symposium on Sustainable Systems and Technology.

Marland, G. \& Schlamadinger, B. 1995. Biomass Fuels and Forest-Management Strategies How Do We Calculate the Greenhouse-Gas Emissions Benefits. Energy, 20(11), 1131$1140 \leq$ Go to $|S|>: / /$ WOS:A1995RY13300005.

Mason, J. E., Fthenakis, V. M., Hansen, T. \& Kim, H. C. 2006. Energy Payback and Life-Cycle Co2 Emissions of the Bos in an Optimized 3.5 Mw Pv Installation. Progress in Photovoltaics: Research and Applications, 14(2), 179-190 https://onlinelibrary.wiley.com/doi/abs/10.1002/pip.652.

Matthews, R. W. 2001. Modelling of Energy and Carbon Budgets of Wood Fuel Coppice Systems. Biomass \& Bioenergy, 21(1), 1-19 <Go to |S|>://WOS:000170151900001.

Mello, F. F., Cerri, C. E., Davies, C. A., Holbrook, N. M., Paustian, K., Maia, S. M., Galdos, M. V., Bernoux, M. \& Cerri, C. C. 2014. Payback Time for Soil Carbon and Sugar-Cane Ethanol. Nature Climate Change, 4(7), 605-609.

Milne, R. \& Brown, T. 1997. Carbon in the Vegetation and Soils of Great Britain. Journal of Environmental Management, 49(4), 413-433. 
Montag, H., Parker, D., Clarkson, T. W. \& Farms, S. The Effects of Solar Farms on Local Biodiversity: A Comparative Study. 2016.

Morton, R. D., Marston, C. G., O'neil, A. W. \& Rowland, C. S. 2020. Land Cover Map 2019 (25m Rasterised Land Parcels, N. Ireland). NERC Environmental Information Data Centre.

Murray, M. \& Petersen, J. Payback and Currencies of Energy, Carbon Dioxide and Money for a $60 \mathrm{Kw}$ Photovoltaic Array. PROCEEDINGS OF THE SOLAR CONFERENCE, 2004. AMERICAN SOLAR ENERGY SOCIETY; AMERICAN INSTITUTE OF ARCHITECTS, 431-438.

Nayak, D. R., Miller, D., Nolan, A., Smith, P. \& Smith, J. U. 2010. Calculating Carbon Budgets of Wind Farms on Scottish Peatlands. Mires and Peat, 4(9), 1-23.

Nelson, J., Gambhir, A. \& Ekins-Daukes, N. 2014. Solar Power for Co2 Mitigation. Grantham Institute for Climate Change Briefing paper No 11, https://www.imperial.ac.uk/media/imperial-college/granthaminstitute/public/publications/briefing-papers/Solar-power-for-CO2-mitigation--Grantham-BP-11.pdf.

Novara, A., Armstrong, A., Gristina, L., Semple, K. T. \& Quinton, J. N. 2012. Effects of Soil Compaction, Rain Exposure and Their Interaction on Soil Carbon Dioxide Emission. Earth Surface Processes and Landforms, 37(9), 994-999 https://onlinelibrary.wiley.com/doi/abs/10.1002/esp.3224.

Nsc, B. 2013. Planning Guidance for the Development of Large Scale Ground Mounted Solar Pv Systems.

Ong, S., Campbell, C., Denholm, P., Margolis, R. \& Heath, G. 2013. Land-Use Requirements for Solar Power Plants in the United States. National Renewable Energy Lab.(NREL), Golden, $\mathrm{CO}$ (United States).

Ostle, N., Levy, P., Evans, C. \& Smith, P. 2009. Uk Land Use and Soil Carbon Sequestration. Land Use Policy, 26, S274-S283.

Pacca, S. \& Moreira, J. R. 2009. Historical Carbon Budget of the Brazilian Ethanol Program. Energy Policy, 37(11), 4863-4873 <Go to IS|>://WOS:000271824600068.

Palmer, D., Gottschalg, R. \& Betts, T. 2019. The Future Scope of Large-Scale Solar in the Uk: Site Suitability and Target Analysis. Renewable energy, 133, 1136-1146.

Peckham, S. D. \& Gower, S. T. 2013. Simulating the Effects of Harvest and Biofuel Production on the Forest System Carbon Balance of the Midwest, USA. Global Change Biology Bioenergy, 5(4), 431-444 <Go to $|S|>: / /$ WOS:000319947300010.

Pehl, M., Arvesen, A., Humpenöder, F., Popp, A., Hertwich, E. G. \& Luderer, G. 2017. Understanding Future Emissions from Low-Carbon Power Systems by Integration of Life-Cycle Assessment and Integrated Energy Modelling. Nature Energy, 2(12), 939945 https://doi.org/10.1038/s41560-017-0032-9.

Pinto, M. A., Frate, C. A., Rodrigues, T. O. \& Caldeira-Pires, A. 2020. Sensitivity Analysis of the Carbon Payback Time for a Brazilian Photovoltaic Power Plant. Utilities Policy, $63 \leq$ Go to $|S|>: / /$ WOS:000527848100007.

Randle-Boggis, R. J., White, P. C. L., Cruz, J., Parker, G., Montag, H., Scurlock, J. M. O. \& Armstrong, A. 2020. Realising Co-Benefits for Natural Capital and Ecosystem Services from Solar Parks: A Co-Developed, Evidence-Based Approach. Renewable and Sustainable Energy Reviews, 125, 109775 http://www.sciencedirect.com/science/article/pii/S136403212030071X.

Reichelstein, S. \& Yorston, M. 2013. The Prospects for Cost Competitive Solar Pv Power. Energy Policy, 55, 117-127 http://www.sciencedirect.com/science/article/pii/S0301421512009688.

Rowland, C. S., Morton, R. D., Carrasco, L., Mcshane, G., O'neil, A. W. \& Wood, C. M. 2017. Land Cover Map 2015 (25m Raster, Gb). NERC Environmental Information Data Centre. 
Schuman, G., Reeder, J., Manley, J., Hart, R. \& Manley, W. 1999. Impact of Grazing Management on the Carbon and Nitrogen Balance of a Mixed-Grass Rangeland. Ecological applications, 9(1), 65-71.

Sma 2018. Non-Financial Report https://www.sma.de/en/company/sustainability.html. Smith, J., Nayak, D. R. \& Smith, P. 2014. Wind Farms on Undegraded Peatlands Are Unlikely to Reduce Future Carbon Emissions. Energy Policy, 66, 585-591.

Smith, J., Perks, M., Gardiner, B., Graves, P., Nayak, D., Xenakis, G., Waldron, S. \& Drew, S. 2011. Carbon Implications of Windfarms Located on Peatlands - Update of the Scottish Government Carbon Calculator Tool.

Smith, P. 2014. Do Grasslands Act as a Perpetual Sink for Carbon? Global Change Biology, 20(9), 2708-2711 https://onlinelibrary.wiley.com/doi/abs/10.1111/gcb.12561.

Solar Trade Association 2019. The Natural Capital Value of Solar. In: GALL, N. \& ROSEWARNE, E. (eds.).

Soussana, J.-F., Loiseau, P., Vuichard, N., Ceschia, E., Balesdent, J., Chevallier, T. \& Arrouays, D. 2004. Carbon Cycling and Sequestration Opportunities in Temperate Grasslands. Soil Use and Management, 20(2), 219-230 https://onlinelibrary.wiley.com/doi/abs/10.1111/j.1475-2743.2004.tb00362.x.

Souza, S. P., De Avila, M. T. \& Pacca, S. 2012. Life Cycle Assessment of Sugarcane Ethanol and Palm Oil Biodiesel Joint Production. Biomass \& Bioenergy, 44, 70-79 $\leq$ Go to |S|>://WOS:000307031900010.

Svtc 2019. Solar Scorecard 2018-19. http://www.solarscorecard.com/2018-19/2018-19SVTC-Solar-Scorecard.pdf: The Silicon Valley Toxics Coalition

Szilágyi, A. \& Gróf, G. 2020. Estimating the Environmental Footprint of a Grid-Connected 20 Mwp Photovoltaic System. Solar Energy, 197, 491-497 https://www.sciencedirect.com/science/article/pii/S0038092X20300360.

Taylor, R., Conway, J., Gabb, O. \& Gillespie, J. 2019. Potential Ecological Impacts of GroundMounted Photovoltaic Solar Panels. Online] Accessed.

Time for Change. ND. Co2 Emissions for Shipping of Goods [Online]. Available: https://timeforchange.org/co2-emissions-for-shipping-of-goods/ [Accessed $15 / 06 / 2021$.

Todde, G., Murgia, L., Carrelo, I., Hogan, R., Pazzona, A., Ledda, L. \& Narvarte, L. 2018. Embodied Energy and Environmental Impact of Large-Power Stand-Alone Photovoltaic Irrigation Systems. Energies, $11(8) \leq$ Go to |S|>://WOS:000446604100189.

Unfccc. Paris Agreement. Report of the Conference of the Parties to the United Nations Framework Convention on Climate Change (21st Session, 2015: Paris). Retrived December, 2015. HeinOnline, 2017.

Vellini, M., Gambini, M. \& Prattella, V. 2017. Environmental Impacts of Pv Technology Throughout the Life Cycle: Importance of the End-of-Life Management for Si-Panels and Cdte-Panels. Energy, 138, 1099-1111 http://www.sciencedirect.com/science/article/pii/S0360544217312069.

Yang, Y. \& Suh, S. 2015. Marginal Yield, Technological Advances, and Emissions Timing in Corn Ethanol's Carbon Payback Time. International Journal of Life Cycle Assessment, 20(2), 226-232 <Go to $|S|>: / / W O S: 000348138000007$.

Zhang, J. \& Xu, L. Y. 2015. Embodied Carbon Budget Accounting System for Calculating Carbon Footprint of Large Hydropower Project. Journal of Cleaner Production, 96, 444-451 <Go to |SI>://WOS:000354342500043. 


\section{Appendices}

\section{Appendix A \\ Average Land Coverage}

\section{Rationale}

Although it is likely that most users will have site specifics available, which should include the total park area and panel coverage, this may not always be the case. Thus, it was deemed useful to have an availability of suggested figures for users, as a guide when specifics are not available (although they should not be used as a substitute). In the context of land use, these suggested figures could provide an estimate of the total park area, panel coverage, access track \& building coverage, and fencing requirements, when the desired capacity is inputted by the user, on the basis of average UK park values.

In order to provide these average values, an ArcGIS Pro database of UK solar parks was consulted (Unpublished data), with its associated excel file summarising content. This database contained digitised maps of all 1032 solar parks, as well as an associated excel file including the park area, panel area and MW capacity (among other information) for all of these sites.

\section{Total Park Area \& Panel Coverage}

Using the information provided by the associated excel file, the area of each park was divided by its MW capacity. These values were summed and divided by the sample number to generate average total park area per MW installed capacity.

The average total park area per MW was found to be 1.961773914 ha from this method. This was then compared to similar values in the literature (Ong et al., 2013). Although the figures were different, this was partially due to the difference in locations (USA vs UK). Solar Trade Association (2019) states that solar parks in the UK currently use between 1.6 and 2 ha per 1 MW capacity, so this corresponds well with the figures derived.

A similar process was followed to determine average panel cover per $\mathrm{MW}$, simply using average panel coverage data in place of total coverage. This produced a value of 1.38420296 ha average panel coverage per MW installed capacity of park, reflecting the smaller area within a park that is covered directly by panels compared to the total boundary area. Although it is not completely accurate to include the panel area as the area shaded (sun will move during 
the day leading to variation), this should be a suitable estimate as the variation throughout the day is likely to cancel out.

\section{Fencing requirements}

As the database also provided information on the perimeter of all 1032 digitised solar parks within the associated excel document, it was decided that this would constitute a suitable estimate of the average fencing requirements for these parks, as it can be assumed that fencing will go along the perimeter of a solar park (NSC, 2013). The perimeter of each park was divided by its MW installed capacity, before these were summed and divided by sample number to generate an average perimeter of $348 \mathrm{~m}$ per MW installed capacity.

\section{Access Track \& Building Coverage}

Since the database did not include information on access track or building coverage (associated with transformers, inverters, energy storage units, DNO substations \& customer substations) within the solar parks, it was deemed that this should be measured from a sample of parks. A description for how this was completed is provided below.

\section{Selecting sample sites}

Due to the large range in park size (69.55 MW), it was deemed useful to group the parks and to randomly select a number of parks from each sample size, so that a variety of park sizes was represented. Using the associated excel spreadsheet, parks were arranged in ascending order based on installed capacity, before being placed into 5 evenly sized groups. Each of the parks was allocated a unique number, and a random number generator was employed to select 10 different parks in each of these groups. This provided a sample of 50 randomly selected solar parks across the full range of installed capacity.

\section{Access tracks}

After the sample of 50 parks had been identified, each of these sites was loaded in ArcGIS Pro individually. The polygon feature was utilised in order to trace each area of access track within the solar park, assigning these shapes the same ID as the park. Criteria for measuring the access tracks is defined below. 
Areas of access tracks were deemed to be those that were of sufficiently different colour to surrounding land, whilst appearing to follow a traditional 'track' shape (i.e., two parallel lines appearing to join together areas of the solar park). Areas that followed this traditional 'track' shape but appeared as the same colour as surrounding areas were not included as these were likely not formally allocated track areas, but instead areas where vehicles had driven recently. The exception to this was when there was obstruction (e.g., tree cover) part of the way along the access track, where it was assumed that both areas of access track would join beneath this. Only areas within the park boundary (as defined by digitised park area) were included when measuring access tracks, with the exception of small areas of track appearing to exit then re-enter the boundary briefly, which was assumed to be due to map resolution. Areas of access tracks were ignored if they appeared to go under panels, as it was assumed that these were from previous land use as it is unlikely vehicles would be moving underneath panels. If a solar park did not appear to have any formal access tracks, a small square was traced at the road entrance, so that it was clear the site had not been missed.

Once the access tracks had been measured on all of the selected sites, the shape area was compiled in the excel spreadsheet. Those sites where it was deemed no access tracks were present were marked as 0 and the rest were left as is. The percentage coverage of the access tracks compared to that of the total park was calculated and recorded within the spreadsheet. This was calculated according to each of the groups and then the overall average coverage for access tracks within the parks, which was found to be $2.25 \%$. This was significantly lower than the suggested $5 \%$ value in (Beylot et al., 2014). This may be due to incorrect measuring of the park boundaries, differences in output (large vs small), or recent changes in practices to minimise tracks in new parks.

\section{Buildings}

The same process followed for measuring access tracks was repeated for measuring building coverage. All buildings were included a single category, due to difficulty identifying the different building types using the low-resolution images provided in ArcGIS Pro. The criteria for measuring building areas are discussed below.

Buildings were measured to be any obvious man-made structure that appeared inside of or on the park boundary defined by the digitised area. If the concrete foundations of the building could be seen, they were assumed to be the outer boundary, if not then the boundary of the building was used instead. Best effort was taken to distinguish between building area and 
shadows, but this may have been subject to some mistakes. Small areas of disturbance were ignored if resolution was too low to properly distinguish if they were a building or just a difference in ground texture (e.g., hole in ground). If buildings were close together (small gap) they were included as the same shape with slight indentation as it is likely their foundations would merge. Objects that were deemed to likely be construction materials (but not construction buildings) were ignored as these would not be permanent fixtures on the site, there may have been some error with this. Anytime there was uncertainty with the nature of a building (whether it was temporary for construction or looked as though it could been there previously), it was included anyway. This meant that the estimates may be slightly higher but this was deemed to be best practice rather than ignoring buildings that could have potentially been vital. The error due to this was deemed to be minimal.

Once the building areas had been measured on all of the selected sites, the shape area was compiled in the excel spreadsheet. The percentage coverage of the access tracks compared to that of the total park was calculated and recorded within the spreadsheet. This was calculated according to each of the groups and then the overall average coverage for access tracks within the parks, which was found to be $0.25 \%$. 